\title{
An enhanced two-source evapotranspiration model for land (ETEML): Algorithm and evaluation
}

\author{
Yongmin Yang a,b,c,*, Hongbo Su ${ }^{\mathrm{d}}$, Renhua Zhang ${ }^{\mathrm{c}}$, Jing Tian ${ }^{\mathrm{c}}$, Lu Li ${ }^{\mathrm{c}, \mathrm{e}}$ \\ a State Key Laboratory of Simulation and Regulation of Water Cycle in River Basin, Beijing 100038, China \\ ${ }^{\mathrm{b}}$ Research Center on Flood and Drought Disaster Reduction of the Ministry of Water Resources, China Institute of Water Resources and Hydropower Research, Beijing 100038, China \\ ' Key Laboratory of Water Cycle E Related Land Surface Processes, Institute of Geographic Sciences and Natural Resources Research, Beijing 100101, China \\ d Department of Civil, Environmental and Geomatics Engineering, Florida Atlantic University, FL 33431, USA \\ e Graduate University of Chinese Academy of Sciences, Beijing 100049, China
}

\section{A R T I C L E I N F O}

\section{Article history:}

Received 10 September 2014

Received in revised form 14 June 2015

Accepted 25 June 2015

Available online 8 July 2015

\section{Keywords:}

Evapotranspiration

Remote sensing

Two-source model

Trapezoid

\begin{abstract}
A B S T R A C T
Satellite remote sensing provides a promising way to estimate regional evapotranspiration (ET) in a spatially distributed manner. In this study, an enhanced two-source evapotranspiration model for land (ETEML) is proposed based on a trapezoid framework of the vegetation fractional cover and land surface temperature (VFC/LST) space. In ETEML, a VFC/LST trapezoid space is theoretically defined for each pixel, and a pixel-wise mixed surface temperature decomposition method is proposed. ETEML is based on a two-source scheme, and the crop water stress index (CWSI) concept is applied to parameterize the soil evaporation and the vegetation transpiration separately. The proposed model was applied to the Soil Moisture-Atmosphere Coupling Experiment (SMACEX) site in central lowa, USA. Evaluation with a remotely sensed dataset from Landsat was carried out to assess the performance of ETEML. Compared with the tower observations, the mean absolute deviation (MAD) and the root mean square deviation (RMSD) for the ETEML estimated latent heat flux (LE) are, respectively, $49 \mathrm{~W} / \mathrm{m}^{2}$ and $59 \mathrm{~W} / \mathrm{m}^{2}$, comparable to retrieval accuracies published in other studies. Comparison between ETEML and variations on a simpler trapezoid interpolation model (TIM1 and TIM2) indicates that ETEML reduces the subjectivity and uncertainties involved in TIM1 and TIM2. Overall, the results suggest that ETEML is promising and can expand the application of the trapezoid framework-based ET modeling approaches to heterogeneous surfaces.
\end{abstract}

(c) 2015 Elsevier Inc. All rights reserved.

\section{Introduction}

Evapotranspiration (ET) is an important process that drives energy and water exchanges between the hydrosphere, atmosphere, and biosphere (Brutsaert, 2005; Eagleson, 2002; Kabat, 2004; Katul, Oren, Manzoni, Higgins, \& Parlange, 2012; Priestley \& Taylor, 1972). The accurate observation and estimation of ET is extremely important to further our understanding of the global climate change, land-atmosphere interaction, water cycle, and ecological studies (Glenn, Huete, Nagler, Hirschboeck, \& Brown, 2007; Kustas \& Anderson, 2009; Sellers et al., 1997; Shuttleworth, 2007; Wang \& Dickinson, 2012). Recent advances in retrieval algorithms and satellite remote sensing technology enable large-scale mapping of ET (Kalma, McVicar, \& McCabe, 2008; Kustas \& Anderson, 2009; Li et al., 2009; Moran et al., 1996). Several global multi-year ET datasets have been derived (Mu, Heinsch, Zhao, \& Running, 2007; Mu, Zhao, \& Running, 2011; Mueller et al., 2011; Zhang et al., 2012). Jiménez et al. (2011) compared 12 monthly mean land surface heat flux products for the period 1993-1995 and found

\footnotetext{
* Corresponding author at: State Key Laboratory of Simulation and Regulation of Water Cycle in River Basin, Beijing 100038, China.

E-mail address: yangym@iwhr.com (Y. Yang).
}

the seasonality was well captured by all products, but large differences in the flux partitioning were observed. Mueller et al. (2013) presented a monthly global ET synthesis product merged from several global data.

Land surface temperature (LST) is widely used in ET modeling and is a key variable for partitioning available energy into a sensible heat flux (H) and latent heat flux (LE) (Anderson, Norman, Mecikalski, Otkin, \& Kustas, 2007a,b; Kalma et al., 2008; Kustas \& Anderson, 2009; Kustas et al., 1989). Single-source models often use LST and empirical resistance corrections to estimate surface heat fluxes. However, due to its highly empirical dependency, this approach would produce significant errors when applied to partially vegetated landscapes (Norman, Kustas, \& Humes, 1995; Timmermans, Kustas, Anderson, \& French, 2007). To overcome these limitations associated with one-source models, two-source models were developed to make use of remotely sensed radiometric surface temperature directly and are preferable over heterogeneous surfaces (Kustas \& Norman, 2000). Accurately decomposing the surface temperature of a mixed pixel into soil and canopy component temperatures is the core of the two-source modeling approach. The two-source energy balance model (TSEB) was proposed by Norman et al. (1995) to estimate $\mathrm{H}$ and LE for the soil and canopy separately using a single measurement of the radiometric surface temperature. 
The spatial contextual models based on the vegetation fractional cover and land surface temperature (VFC/LST) space are an important modeling scheme. A key advantage of this group of approaches is its relative independence from site-specific tuning of model parameters (Carlson, 2007; Petropoulos, Carlson, Wooster, \& Islam, 2009). Such models are collectively referred to here as "trapezoid interpolation models (TIMs)." Related research includes the works by Moran, Clarke, Inoue, and Vidal (1994), Jiang and Islam (2001, 2003), Zhang et al. (2005), Zhang et al. (2008), Wang, Li, and Cribb (2006), Stisen, Sandholt, Norgaard, Fensholt, and Jensen (2008), and Shu, Stisen, Jensen, and Sandholt (2011). Recently, a novel two-source model called the pixel component arranging and comparing algorithm (PCACA) was presented by Zhang et al. (2005) and Zhang (2009) to estimate soil evaporation and vegetation transpiration separately. Most importantly, a new operational way to retrieve land surface component temperatures was proposed by Zhang et al. (2005) and Zhang (2009) based on the interpretation of the pixel distribution in the VFC/LST space (Carlson, 2007; Moran et al., 1994; Petropoulos et al., 2009). The temperature decomposition method was further applied by Long and Singh (2012) and Yang and Shang (2013) to develop their own models. However, several critical issues are related with the application of TIMs: (1) The application of this type of model needs a spatial region large enough to have a wide range of soil wetness and vegetation fractional cover and a spatially homogeneous meteorological forcing (Carlson, 2007; Long \& Singh, 2012; Petropoulos et al., 2009; Zhang et al., $2005,2008)$. This requirement greatly hampered the application of TIMs to heterogeneous surfaces and a large-scale study (Li et al., 2009). (2) The correct determination of the dry edge and the wet edge is crucial for TIMs (Tang, Li, \& Tang, 2010; Zhang et al., 2005, 2008). (3) The assumptions involved in the VFC/LST trapezoid space require more careful study. The assumption that the isoline or the mixed surface temperature in the VFC/LSF trapezoid space is mainly controlled by soil water availability must be satisfied in TIMs. Zhang et al. (2008) realized this issue and tried to eliminate the effects of four controlling factors (air temperature, albedo, water vapor pressure, and aerodynamic resistance) on land surface temperature and made two improvements on the PCACA algorithm. However, these improvements still have limitations, and the assumption is still not fully satisfied. In the method proposed by Zhang et al. (2008), the average values of the air temperature, albedo, water vapor pressure, and aerodynamic resistance in the entire image are assigned to each pixel, and a new surface temperature is calculated. The calculated temperature cannot represent the actual temperature of the underlying surface, and this method needs complex temperature transformations. (4) It is difficult to couple TIMS with other models. Tian et al. (2013) indicated that different dry/wet edges determined in the VFC/LST trapezoid space directly led to the deviation of ET estimates due to the variation of the spatial domain size. This domain-dependent problem led to difficulty with this type of model being coupled with other pixel-based models.

The objective of this study is to develop an enhanced two-source evapotranspiration model for land (ETEML) to overcome critical issues related to TIMs by defining a theoretical VFC/LST space for each pixel. Section 2 includes two sub-sections. Section 2.1 presents a description of the conventional trapezoid interpolation model, and Section 2.2 introduces the two-source model scheme, the determination of the theoretical VFC/LST trapezoid space, and the temperature decomposition method applied in ETEML. Section 3 introduces the datasets used to assess the model. Section 4 first reports the results of the model applied at the regional scale with input variables retrieved from Landsat imagery. In the remainder of Section 4, ETEML is compared to results from two conventional TIMs. Section 5 discusses the advantages and limitations in this work, and the final section provides a conclusion.

\section{Model description}

\subsection{Trapezoid interpolation model (TIM)}

In this section, two conventional TIMs are described and were used as control cases in this study. The TIM is based on an interpretation of pixel distribution in the VFC/LST space (Carlson, 2007; Petropoulos et al., 2009). The VFC/LST space, established under the conditions of full ranges of soil moisture content and vegetation, is characteristic of being bounded with a trapezoid envelope or a triangle envelope. A conceptual illustration of the VFC/LST space is shown in Fig. 1(a). There are four extreme points within the trapezoid envelope: Point $A$ represents a dry, bare soil surface; Points B and C represent a fully vegetated area with severe water stress and no water limitations, respectively; and Point D represents a wet, bare surface. As a result, the dry edge of the trapezoid space is determined by Points $A$ and $B$, and the cold edge is determined by Points $C$ and $D$. The dry edge represents a boundary with minimal soil water content and ET. Points along the cold edge are assumed to have maximum soil water content and ET equal to the potential rate. Moran et al. (1994) introduced a water deficit index (WDI) based on the VFC/LST trapezoid space and extended the application of CWSI to the partially vegetated surface areas.

$\mathrm{WDI}=1-\frac{\mathrm{LE}}{\mathrm{E}_{\mathrm{p}}}=\frac{\mathrm{a}}{\mathrm{a}+\mathrm{b}}$

where $E_{p}$ is the potential evaporation rate $\left(\mathrm{W} / \mathrm{m}^{2}\right), \mathrm{b}$ is the temperature difference between Point $\mathrm{M}$ and the dry edge, and $\mathrm{a}$ is the temperature difference between Point $\mathrm{M}$ and the cold edge (Fig. 1[a]). In this study, the Priestley-Taylor equation is adopted to compute the potential evaporation, and $\mathrm{LE}\left(\mathrm{W} / \mathrm{m}^{2}\right)$ is then estimated using:

$\mathrm{LE}=1.26 \frac{\Delta}{\Delta+\gamma}\left(\mathrm{R}_{\mathrm{n}}-\mathrm{G}\right) \cdot(1-\mathrm{WDI})$

where $\Delta$ is the slope of the saturation vapor pressure curve at air temperature $\left(\mathrm{kPa}^{\circ} \mathrm{C}^{-1}\right)$, and $\gamma$ is the psychrometric constant $\left(\mathrm{kPa}^{\circ} \mathrm{C}^{-1}\right)$. $R_{n}$ is the net radiation $\left(W / m^{2}\right)$, which is calculated from:

$\mathrm{R}_{\mathrm{n}}=(1-\alpha) \mathrm{S}_{\mathrm{wd}}+\varepsilon \delta\left(\varepsilon_{\mathrm{a}} \mathrm{T}_{\mathrm{a} \_\mathrm{k}}^{4}-\mathrm{LST}^{4}\right)$

where $S_{w d}$ is the downwelling shortwave radiation $\left(\mathrm{W} / \mathrm{m}^{2}\right)$ and $\delta$ is the Stefen-Boltzman constant. $T_{a \_k}$ is air temperature; LST is the radiative land surface temperature $(\mathrm{K}) ; \varepsilon$ is the emissivity of the land surface; $\varepsilon_{\mathrm{a}}$ is the emissivity of the atmosphere and $\alpha$ is the surface albedo. In this study, $\alpha$ was estimated from the visible and nearinfrared bands of the Landsat image following Tasumi, Allen, and Trezza (2008). The soil heat flux $\mathrm{G}\left(\mathrm{W} / \mathrm{m}^{2}\right)$ was estimated using the equation proposed by Bastiaanssen, Menenti, Feddes, and Holtslag (1998), Bastiaanssen, Pelgrum, et al. (1998):

$\mathrm{G}=\mathrm{R}_{\mathrm{n}}(\mathrm{LST}-273.15)(0.0038+0.0074 \alpha)\left(1-0.98 \mathrm{NDVI}^{4}\right)$.

The determination of the trapezoid space is crucial for TIMs. Generally speaking, there are two kinds of methodologies to determine the dry edge. For the first one, the dry edge and wet edge are retrieved empirically from the scatter plot defined by vegetation fractional cover and land surface temperature. One good example is Tang et al. (2010), who proposed an automatic method to determine the dry and wet edges of the VFC/LST space. However, this method is not feasible in this study, because the trapezoid space is not very clear in the scatter plot defined by VFC and LST derived from Landsat. Therefore, four extremes are selected manually, as in Choi et al. (2009). This method was called TIM1. For the second one, the dry edge is determined using theoretical boundary conditions by solving for energy balance and radiation budget equations (Long \& Singh, 2012; Yang \& Shang, 2013; Zhang, 2009; Zhang 

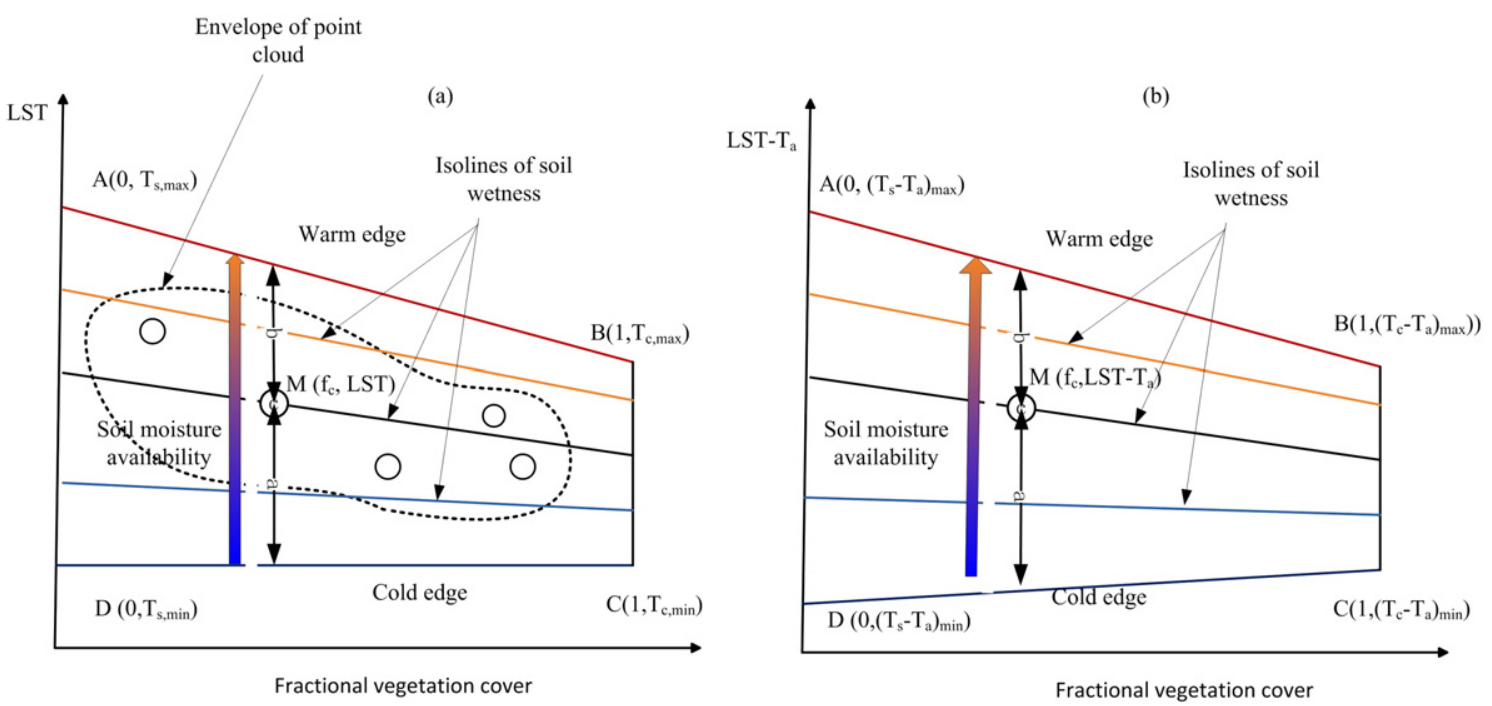

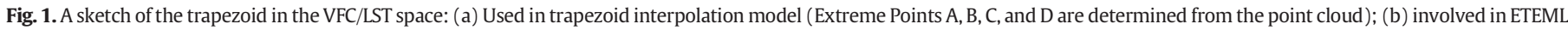
(Extreme Points A, B, C, and D are theoretically determined from the related information from point M).

et al., 2008). This type of method greatly reduces subjectivity and uncertainties related with the specification of the dry edge. This method is called TIM2.

Three important issues related to TIMs remain unresolved: (1) The application of TIMs is restricted to a flat surface with homogeneous meteorological forcing (Moran et al., 1994; Petropoulos et al., 2009). This greatly hampered the application of TIMs over a large-scale study area with heterogeneous surfaces and forcings. (2) Uncertainties and subjectivity are involved in the application of TIMs (Carlson, 2007). In most applications, four extreme points defining the trapezoid space are subjectively selected from a scatter plot. Small changes in these selections can greatly impact the model performance. (3) The crucial assumption is that LST is mainly controlled by soil water availability, and soil water availability can be represented by the configuration of the VFC/ LST space (Carlson, 2007; Zhang et al., 2008). But this assumption is rarely satisfied. LST is related to complex surface-atmosphere interaction and is controlled by energy balance and radiation budget equations (see Equation [16] in Long and Singh (2012)). If other controlling factors (such as albedo, aerodynamic resistance, and air temperature, among others) on land surface temperature are not considered, the derivation of evaporation from the VFC/LST trapezoid space would definitely involve uncertainties (Zhang et al., 2008).

\subsection{An enhanced two-source evapotranspiration model for land (ETEML)}

The enhanced two-source ET modeling (ETEML) approach described here attempts to address some of the shortcomings in current TIMbased modeling. Section 2.2.1 presents a description of the two-source model scheme. Section 2.2.2 introduces the theoretical VFC/LST trapezoid space and its determination, and Section 2.2.3 introduces the temperature decomposition method based on the VFC/LST space.

\subsubsection{Two-source model scheme}

The energy balance equation can be formulated for the whole canopy-soil system, as well as the canopy and soil components, as follows:

$\mathrm{R}_{\mathrm{n}}=\mathrm{H}+\mathrm{LE}+\mathrm{G}$

$\mathrm{R}_{\mathrm{nc}}=\mathrm{H}_{\mathrm{c}}+\mathrm{LE}_{\mathrm{c}}$

$\mathrm{R}_{\mathrm{ns}}=\mathrm{H}_{\mathrm{s}}+\mathrm{LE}_{\mathrm{s}}+\mathrm{G}$ where $R_{n}$ is the net radiation flux $\left(W / m^{2}\right)$, and $H$ is the sensible heat flux $\left(\mathrm{W} / \mathrm{m}^{2}\right)$. The subscripts $C$ and $S$ indicate canopy and soil, respectively.

The partitioning of the different fluxes into soil and canopy components was accomplished based on a patch approach (Long \& Singh, 2012; Sanchez, Kustas, Caselles, \& Anderson, 2008):

$\mathrm{R}_{\mathrm{n}}=\mathrm{f}_{\mathrm{c}} \mathrm{R}_{\mathrm{nc}}+\left(1-\mathrm{f}_{\mathrm{c}}\right) \mathrm{R}_{\mathrm{ns}}$

$\mathrm{H}=\mathrm{f}_{\mathrm{c}} \mathrm{H}_{\mathrm{c}}+\left(1-\mathrm{f}_{\mathrm{c}}\right) \mathrm{H}_{\mathrm{s}}$

$\mathrm{LE}=\mathrm{f}_{\mathrm{c}} \mathrm{LE}_{\mathrm{c}}+\left(1-\mathrm{f}_{\mathrm{c}}\right) \mathrm{LE}_{\mathrm{s}}$

where $f_{c}$ is the fractional vegetation cover. $R_{n c}$ and $R_{n s}$ are estimated using the long-wave and the short-wave radiation separately for the canopy and soil component:

$\mathrm{R}_{\mathrm{nc}}=\left(1-\alpha_{\mathrm{c}}\right) \mathrm{S}+\varepsilon_{\mathrm{c}} \mathrm{L}_{\mathrm{sky}}-\varepsilon_{\mathrm{c}} \sigma \mathrm{T}_{\mathrm{c}}^{4}$

$\mathrm{R}_{\mathrm{ns}}=\left(1-\alpha_{\mathrm{s}}\right) \mathrm{S}+\varepsilon_{\mathrm{s}} \mathrm{L}_{\mathrm{sky}}-\varepsilon_{\mathrm{s}} \sigma \mathrm{T}_{\mathrm{s}}^{4}$

where $S$ is the incident solar radiation on ground $\left(\mathrm{W} / \mathrm{m}^{2}\right)$, and $\alpha_{\mathrm{c}}$ and $\alpha_{\mathrm{s}}$ are canopy and soil albedos, respectively. $\sigma$ is the Stefan-Boltzmann constant; $L_{\text {sky }}$ is the incident long-wave radiation $\left(\mathrm{W} / \mathrm{m}^{2}\right) . \mathrm{T}_{\mathrm{c}}$ and $\mathrm{T}_{\mathrm{s}}$ are canopy and soil temperatures, respectively. Surface albedo for every pixel is assumed to be weighted by vegetation and soil components (Zhang et al., 2005, 2008):

$\alpha=\mathrm{f}_{\mathrm{c}} \alpha_{\mathrm{c}}+\left(1-\mathrm{f}_{\mathrm{c}}\right) \alpha_{\mathrm{s}}$

where $\alpha$ is the albedo for a composite pixel. $\alpha_{c}$ is then estimated using the method given by Campbell and Norman (1998). $\alpha_{s}$ can be derived from the above equation. $G$ is parameterized as a fraction (0.31) of the net radiation above the soil surface $\left(\mathrm{R}_{\mathrm{ns}}\right)$ following Choudhury, Idso, and Reginato (1987).

A complete and independent energy balance between the atmosphere and each component of the surface is established. The component fluxes to the total sensible heat flux can be written as follows:

$\mathrm{H}_{\mathrm{c}}=\rho \mathrm{C}_{\mathrm{p}} \frac{\mathrm{T}_{\mathrm{c}}-\mathrm{T}_{\mathrm{a}}}{\mathrm{r}_{\mathrm{a}}^{\mathrm{h}}}$

$\mathrm{H}_{\mathrm{s}}=\rho \mathrm{C}_{\mathrm{p}} \frac{\mathrm{T}_{\mathrm{s}}-\mathrm{T}_{\mathrm{a}}}{\mathrm{r}_{\mathrm{a}}^{\mathrm{a}}+\mathrm{r}_{\mathrm{a}}^{\mathrm{s}}}$ 
where $\rho$ is the air density $\left(\mathrm{kg} / \mathrm{m}^{3}\right)$, and $C_{p}$ is the specific heat of air at constant pressure $\left(\mathrm{J} / \mathrm{kg} \cdot{ }^{\circ} \mathrm{C}\right) . \mathrm{r}_{\mathrm{a}}^{\mathrm{h}}$ is the aerodynamic resistance to heat transfer between the canopy and reference height $(\mathrm{s} / \mathrm{m}) \cdot \mathrm{r}_{\mathrm{a}}^{\mathrm{a}}(\mathrm{s} / \mathrm{m})$ was calculated according to Sanchez et al. (2008). $\mathrm{r}_{\mathrm{a}}^{\mathrm{s}}$ is the aerodynamic resistance to the heat flow in the boundary layer immediately above the soil surface $(\mathrm{s} / \mathrm{m})$. The description to estimate these aerodynamic resistances can be found in the appendix of Sanchez et al. (2008).

Plant foliage temperatures have been shown to be closely correlated with plant transpiration (Jackson, Idso, Reginato, \& Pinter, 1981; Jackson, Kustas, \& Choudhury, 1988). The crop water stress index (CWSI) for the canopy component can be expressed as follows:

$\mathrm{CWSI}_{\mathrm{c}}=1-\frac{\mathrm{LE}_{\mathrm{c}}}{\mathrm{EP}_{\mathrm{c}}}=\frac{\left(\mathrm{T}_{\mathrm{c}}-\mathrm{T}_{\mathrm{a}}\right)-\left(\mathrm{T}_{\mathrm{c}}-\mathrm{T}_{\mathrm{a}}\right)_{\mathrm{cmin}}}{\left(\mathrm{T}_{\mathrm{c}}-\mathrm{T}_{\mathrm{a}}\right)_{\mathrm{cmax}}-\left(\mathrm{T}_{\mathrm{c}}-\mathrm{T}_{\mathrm{a}}\right)_{\mathrm{cmin}}}$

where $T_{a}$ is the air temperature $\left({ }^{\circ} \mathrm{C}\right) \cdot\left(T_{c}-T_{a}\right)$ is the measured canopy temperature minus air temperature. $\left(\mathrm{T}_{\mathrm{c}}-\mathrm{T}_{\mathrm{a}}\right)_{\mathrm{cmax}}$ and $\left(\mathrm{T}_{\mathrm{c}}-\mathrm{T}_{\mathrm{a}}\right)_{\mathrm{cmin}}$ are the theoretical upper and lower limits of $\left(\mathrm{T}_{\mathrm{c}}-\mathrm{T}_{\mathrm{a}}\right)$. The aerodynamic resistance for theoretical limits of the canopy component corresponds to Eq. (14). The CWSI can also be applied to the soil component (Moran et al., 1994), giving rise to the soil water deficit index (SWDI) written as:

$\mathrm{SWDI}_{\mathrm{s}}=1-\frac{\mathrm{LE}_{\mathrm{s}}}{\mathrm{EP}_{\mathrm{S}}}=\frac{\left(\mathrm{T}_{\mathrm{s}}-\mathrm{T}_{\mathrm{a}}\right)-\left(\mathrm{T}_{\mathrm{s}}-\mathrm{T}_{\mathrm{a}}\right)_{\mathrm{smin}}}{\left(\mathrm{T}_{\mathrm{s}}-\mathrm{T}_{\mathrm{a}}\right)_{\mathrm{smax}}-\left(\mathrm{T}_{\mathrm{s}}-\mathrm{T}_{\mathrm{a}}\right)_{\operatorname{smin}}}$

where $\left(T_{s}-T_{a}\right)$ is the measured soil surface temperature minus air temperature. $\left(T_{s}-T_{a}\right)_{s m a x}$ and $\left(T_{s}-T_{a}\right)_{s m i n}$ are the theoretical upper and lower limits of $\left(T_{s}-T_{a}\right)$. The aerodynamic resistance for theoretical limits of soil component corresponds to Eq. (15). The derivation of the $\left(T_{c}-T_{a}\right)_{c \max },\left(T_{c}-T_{a}\right)_{c m i n},\left(T_{s}-T_{a}\right)_{s m a x}$, and $\left(T_{s}-T_{a}\right)_{s m i n}$ can be found in Jackson et al. (1988) and the appendix of Moran et al. (1994).

The component fluxes to the total latent heat flux can be derived as follows:

$\mathrm{LE}_{\mathrm{c}}=\left(1-\mathrm{CWSI}_{\mathrm{c}}\right) \mathrm{EP}_{\mathrm{c}}$

$\mathrm{LE}_{\mathrm{s}}=\left(1-\mathrm{SWDI}_{\mathrm{s}}\right) \mathrm{EP}_{\mathrm{s}}$

$\mathrm{EP}_{\mathrm{c}}$ and $\mathrm{EP}_{\mathrm{s}}$ are the potential evaporation rates of the canopy and soil components, respectively. Potential canopy transpiration is computed using:

$\mathrm{EP}_{\mathrm{c}}=\frac{\Delta}{\Delta+\gamma} \mathrm{R}_{\mathrm{nc}}+\frac{\gamma}{\Delta+\gamma} \mathrm{E}_{\mathrm{a}}$

For the $\mathrm{E}_{\mathrm{a}}\left(\mathrm{W} / \mathrm{m}^{2}\right)$ term, the equation proposed by Brutsaert (1982) was applied in this study. Potential soil evaporation is estimated as follows.

$\mathrm{EP}_{\mathrm{s}}=1.26 \frac{\Delta}{\Delta+\gamma}\left(\mathrm{R}_{\mathrm{ns}}-\mathrm{G}\right)$

After $\mathrm{T}_{\mathrm{S}}$ and $\mathrm{T}_{\mathrm{C}}$ are derived or estimated, the above equations can be solved, and the component fluxes can be derived.

\subsubsection{Theoretical VFC/LST trapezoid space}

Soil surface temperature and canopy temperature are two indispensable input variables in the model formulation described in Section 2.2.1. In this study, a theoretical VFC/LST trapezoid space is defined for each pixel and a physical pixel-based surface temperature decomposition method is proposed. A theoretical VFC/LST trapezoid space defined for each pixel is shown in Fig. 1(b). The surface-to-air temperature gradient (LST- $\mathrm{T}_{\mathrm{a}}$ ) is used to replace LST in the trapezoid space. Following the equations from Moran et al. (1994), the four theoretical extreme points can be derived. That is, for the dry bare soil of Point A, evaporation equals zero and the difference between LST and
$\mathrm{T}_{\mathrm{a}}$ can be derived as follows:

$\left(\mathrm{T}_{\mathrm{s}}-\mathrm{T}_{\mathrm{a}}\right)_{\max }=\left[\mathrm{r}_{\mathrm{a}}\left(\mathrm{R}_{\mathrm{n}}-\mathrm{G}\right) / \rho_{\mathrm{a}} \mathrm{C}_{\mathrm{p}}\right]$.

For the saturated bare soil of Point D, where the surface resistance equals zero,

$\left(\mathrm{T}_{\mathrm{s}}-\mathrm{T}_{\mathrm{a}}\right)_{\min }=\left[\left(\mathrm{r}_{\mathrm{a}}\left(\mathrm{R}_{\mathrm{n}}-\mathrm{G}\right)\right) /\left(\rho_{\mathrm{a}} \mathrm{C}_{\mathrm{p}}\right)\right][\gamma /(\Delta+\gamma)]-[\mathrm{VPD} /(\Delta+\gamma)]$.

For the well-watered, full-cover vegetation of Point C,

$$
\begin{gathered}
\left(\mathrm{T}_{\mathrm{c}}-\mathrm{T}_{\mathrm{a}}\right)_{\min }=\left[\left(\mathrm{r}_{\mathrm{a}}\left(\mathrm{R}_{\mathrm{n}}-\mathrm{G}\right)\right) /\left(\rho_{\mathrm{a}} \mathrm{C}_{\mathrm{p}}\right)\right]\left[\gamma\left(1+\mathrm{r}_{\mathrm{cp}} / \mathrm{r}_{\mathrm{a}}\right) /\left(\Delta+\gamma\left(1+\mathrm{r}_{\mathrm{cp}} / \mathrm{r}_{\mathrm{a}}\right)\right)\right] \\
-\left[\operatorname{VPD} /\left(\Delta+\gamma\left(1+\mathrm{r}_{\mathrm{cp}} / \mathrm{r}_{\mathrm{a}}\right)\right)\right] .
\end{gathered}
$$

For the water-stressed, full-cover vegetation of Point B,

$$
\begin{aligned}
\left(\mathrm{T}_{\mathrm{c}}-\mathrm{T}_{\mathrm{a}}\right)_{\max }= & {\left[\left(\mathrm{r}_{\mathrm{a}}\left(\mathrm{R}_{\mathrm{n}}-\mathrm{G}\right)\right) /\left(\rho_{\mathrm{a}} \mathrm{C}_{\mathrm{p}}\right)\right]\left[\gamma\left(1+\mathrm{r}_{\mathrm{cx}} / \mathrm{r}_{\mathrm{a}}\right) /\left(\Delta+\gamma\left(1+\mathrm{r}_{\mathrm{Cx}} / \mathrm{r}_{\mathrm{a}}\right)\right)\right] } \\
& -\left[\mathrm{VPD} /\left(\Delta+\gamma\left(1+\mathrm{r}_{\mathrm{cx}} / \mathrm{r}_{\mathrm{a}}\right)\right)\right]
\end{aligned}
$$

where VPD is the vapor pressure deficit of the air at air temperature $\mathrm{T}_{\mathrm{a}}(\mathrm{kPa}), \gamma$ is the psychrometric constant $\left(\mathrm{kPa}^{\circ} \mathrm{C}^{-1}\right), \mathrm{r}_{\mathrm{a}}$ is the aerodynamic resistance $(\mathrm{s} / \mathrm{m})$, and the description to estimate $r_{a}$ can be found in the appendix of Moran et al. (1994). $\mathrm{r}_{\mathrm{cp}}$ is the canopy resistance at potential evapotranspiration $(\mathrm{s} / \mathrm{m})$, and $\mathrm{r}_{\mathrm{cx}}$ is the maximum canopy resistance $(\mathrm{s} / \mathrm{m})$. Values for $\mathrm{r}_{\mathrm{cx}}$ and $\mathrm{r}_{\mathrm{cp}}$ are published for many agricultural crops (Allen, Pereira, Raes, \& Smith, 1998). If the values are not available, $r_{\mathrm{cp}}=25-100 \mathrm{~s} / \mathrm{m}$ and $\mathrm{r}_{\mathrm{cx}}=1000-1500 \mathrm{~s} / \mathrm{m}$ would be reasonable values and will not result in an appreciable error (Moran et al., 1994). In the ETEML algorithm, a theoretical VFC/LST space is constructed for each pixel based on that pixel's values of $R_{n}, G, T_{a}$, and VPD. The point $M$ is located within that space at coordinates $f_{c}, L S T-T_{a}$, and the water deficit index is derived for each pixel based on its point $M$ and trapezoid edges.

\subsubsection{The temperature decomposition method}

The temperature decomposition method proposed by Zhang et al. (2005) is based on the interpretation of the pixel distribution in the VFC/LST space. Two assumptions need to be satisfied in this method. First, it is assumed that the configuration of the VFC/LST space is primarily determined by the variation of soil water availability. Second, the isolines of equal soil water content exist in the VFC/LST space. Previous studies have demonstrated that there are isolines of surface soil wetness/Temperature-Vegetation Dryness Index (TVDI) within the VFC/LST trapezoid space (Carlson, 2007; Gillies, Carlson, Cui, Kustas, \& Humes, 1997; Sandholt, Rasmussen, \& Andersen, 2002; Wang et al., 2006; Zhang et al., 2005). Zhang et al. (2005) indicated that soil surface temperatures/canopy temperatures for all pixels at an isoline with the same soil surface moisture availability are equivalent, and the mixed radiometric temperature is weighted by soil surface temperature and canopy temperature with the variation of a fractional vegetation cover. The slope of each isoline can be derived by interpolating the slope of the dry edge and that of the cold edge. Then, the soil surface temperature and vegetation canopy temperature can be derived. The determination of the trapezoid space is particularly important for the temperature decomposition method. A more detailed mathematical description of the temperature decomposition method based on the VFC/LST space can be found in the papers by Zhang (2009) and Zhang et al. (2005).

Based on the theoretical VFC/LST trapezoid space described in Section 2.2.2, the composite radiometric surface temperature of each pixel can be decomposed to soil and canopy component temperatures (Long \& Singh, 2012; Yang \& Shang, 2013; Zhang et al., 2005, 2008):

$\mathrm{T}_{\mathrm{s}}-\mathrm{T}_{\mathrm{a}}=\left(\mathrm{LST}-\mathrm{T}_{\mathrm{a}}\right)-\mathrm{K}_{\mathrm{s}} * \mathrm{f}_{\mathrm{c}}$
$\mathrm{T}_{\mathrm{c}}-\mathrm{T}_{\mathrm{a}}=\mathrm{K}_{\mathrm{s}} *\left(1-\mathrm{f}_{\mathrm{c}}\right)+\left(\mathrm{LST}-\mathrm{T}_{\mathrm{a}}\right)$ 
where $K_{s}$ is the slope of the isoline that passes through point $M$ and can be derived by interpolating the slope of the dry edge and that of the cold edge:

$\mathrm{K}_{\mathrm{s}}=\mathrm{K}_{\mathrm{s}, \mathrm{dry}}+\frac{\mathrm{b}}{\mathrm{a}+\mathrm{b}}\left[\mathrm{K}_{\mathrm{s}, \text { wet }}-\mathrm{K}_{\mathrm{s}, \mathrm{dry}}\right]$

where $\mathrm{K}_{\mathrm{s} \text {,dry }}$ and $\mathrm{K}_{\mathrm{s} \text {,wet }}$ are the slopes of the dry edge and the wet edge, respectively. $\mathrm{b}$ is the temperature difference between Point $\mathrm{M}$ and the warm edge, and $\mathrm{a}$ is the temperature difference between Point $\mathrm{M}$ and the cold edge (Fig. 1[b]). The slopes of the dry edge and the wet edge can be derived as follows:

$\mathrm{K}_{\mathrm{s}, \mathrm{dry}}=\left(\mathrm{T}_{\mathrm{c}}-\mathrm{T}_{\mathrm{a}}\right)_{\max }-\left(\mathrm{T}_{\mathrm{s}}-\mathrm{T}_{\mathrm{a}}\right)_{\max }$

$\mathrm{K}_{\mathrm{s}, \text { wet }}=\left(\mathrm{T}_{\mathrm{c}}-\mathrm{T}_{\mathrm{a}}\right)_{\min }-\left(\mathrm{T}_{\mathrm{s}}-\mathrm{T}_{\mathrm{a}}\right)_{\min }$

$\mathrm{a}=\left(\mathrm{LST}-\mathrm{T}_{\mathrm{a}}\right)-\left(1-\mathrm{f}_{\mathrm{c}}\right) \mathrm{K}_{\mathrm{s}, \text { wet }}-\left(\mathrm{T}_{\mathrm{c}}-\mathrm{T}_{\mathrm{a}}\right)_{\min }$

$\mathrm{b}=\left(1-\mathrm{f}_{\mathrm{c}}\right)\left(\mathrm{T}_{\mathrm{s}}-\mathrm{T}_{\mathrm{a}}\right)_{\max }+\mathrm{f}_{\mathrm{c}}\left(\mathrm{T}_{\mathrm{c}}-\mathrm{T}_{\mathrm{a}}\right)_{\max }-\left(\mathrm{T}_{\mathrm{LST}}-\mathrm{T}_{\mathrm{a}}\right)$.

Once $\mathrm{T}_{\mathrm{s}}$ and $\mathrm{T}_{\mathrm{c}}$ were derived, the equations described in Section 2.2.1 can be solved, and the component fluxes can be derived.

\section{Study area and data processing}

\subsection{Region description}

The Soil Moisture-Atmosphere Coupling Experiment (SMACEX) was conducted in conjunction with the Soil Moisture Experiment 2002 (SMEX02) during June and July 2002 near Ames, Iowa. The SMACEX study was designed to provide direct measurement/remote sensing/modeling approaches for understanding the impact of spatial and temporal variability in vegetation cover, soil moisture, and other land surface states on the turbulent flux exchange with the atmosphere. A full description the SMACEX experiment can be found in Kustas, Hatfield, and Prueger (2005). The climate at this site is sub-humid, and the annual average rainfall is approximately $835 \mathrm{~mm}$. The Walnut Creek watershed was the core study area of this experiment. The land cover in the experiment area is primarily composed of corn and soybean. The dataset that consists of extensive measurements of atmospheric, vegetation, and soil properties and fluxes allows for rigorous analysis and the validation of fluxes, which are estimated using remote sensing methods (Choi et al., 2009; Gonzalez-Dugo et al., 2009).

\subsection{Remote sensing data and variable derivation}

The ETEML model was applied over the SMACEX experiment site using remote sensing data from the Landsat satellite and regional meteorological data. Two Landsat scenes were used: one from the Landsat-5 Thematic Mapper (TM) on June 23, 2002 (DOY 174) and a second scene on July 1, 2002 (DOY 182) from the Enhanced Thematic Mapper plus $(\mathrm{ETM}+)$ on Landsat 7 . The remote sensing dataset was obtained from the National Snow and Ice Data Center (http://nsidc.org/index.html).

The land surface temperature is derived from the thermal infrared band (TIR, band 6). The atmospheric transmittance, spectral radiance, and downwelling sky radiance from the atmosphere were provided by Li et al. (2004). The visible, near-infrared (NIR) bands were resampled to be consistent with the thermal infrared band. Details concerning the atmospheric correction and retrieval of land surface temperature are given in Li et al. (2004) and Li, Kustas, Prueger, Neale, and Jackson (2005). Albedo was retrieved from the visible and nearinfrared bands $(1-5,7)$ of the Landsat images following Tasumi et al. (2008) and Allen, Tasumi, Morse, et al. (2007), Allen, Tasumi, and Trezza (2007). The land cover classification for the study area was obtained from the National Snow and Ice Data Center (http://nsidc.org/ index.html).
Empirical relationships between the Landsat-derived vegetation index and the leaf area index, vegetation cover fraction, and crop height over the watershed were given by Anderson et al. (2004). In this study, these empirical relationships were used to derive the leaf area index and vegetation height for the SMACEX region. For both corn and soybean, the leaf area index was derived using the following equation:

$\mathrm{LAI}=(2.88 \mathrm{NDWI}+1.14)(1+0.104 \exp (4.1 \mathrm{NDWI}))$.

Vegetation heights for corn $\left(\mathrm{h}_{\text {corn }}\right)$ and soybean $\left(\mathrm{h}_{\text {soybean }}\right)$ are derived using the following equations:

$\mathrm{h}_{\text {corn }}=(1.2 \mathrm{NDWI}+0.6)(1+0.04 \exp (5.3 \mathrm{NDWI}))$

$\mathrm{h}_{\text {soybean }}=(0.5 \mathrm{NDWI}+0.26)(1+0.005 \exp (4.5 \mathrm{NDWI}))$

where NDWI is the normalized difference water index, which can be computed from the near-infrared (NIR, band 4) and shortwave infrared (SWIR, band5) reflectances:

$\mathrm{NDWI}=(\mathrm{NIR}-\mathrm{SWIR}) /(\mathrm{NIR}+\mathrm{SWIR})$.

The vegetation fractional cover was estimated from the normalized difference vegetation index (NDVI):

$\mathrm{f}_{\mathrm{c}}=1-\left(\frac{\mathrm{NDVI}-\mathrm{NDVI}_{\min }}{\mathrm{NDVI}_{\max }-\mathrm{NDVI}_{\min }}\right)^{\mathrm{k}}$

where $\mathrm{NDVI}_{\text {max }}$ and $\mathrm{NDVI}_{\text {min }}$ are NDVI values for complete vegetation cover and bare soil, respectively. The coefficient $\mathrm{k}$ is a function of the leaf orientation distribution within the canopy. $\mathrm{k}$ is set as 0.6175 in this study, as suggested by Li et al. (2005).

\subsection{Tower measurements}

Twelve towers with eddy covariance (EC) were deployed in the central area of the experiment. There were 6 corn sites and 6 soybean sites. The towers were instrumented with sensors to measure turbulent fluxes and soil heat flux. The distribution of the flux towers and land use classifications are provided in Fig. 2. It is well recognized that the field measurements of heat fluxes using the eddy covariance technique often fail to show closure of the surface energy budget (Foken, 2008; Foken, Wimmer, Mauder, Thomas, \& Liebethal, 2006; Leuning, van Gorsel, Massman, \& Isaac, 2012). During SMACEX, the energy balance closure is 0.71 for the soybean sites and 0.84 for corn sites ( $\mathrm{Su}$, McCabe, Wood, Su, \& Prueger, 2005). For comparison with model flux partitioning, where energy balance is inherently assumed, the measured LE and $\mathrm{H}$ were adjusted for closure errors using the approach suggested by Twine et al. (2000), which conserves the observed Bowen ratio. For a detailed discussion of the flux tower observations and measurement uncertainty during SMACEX, see Kustas et al. (2005) and Prueger et al. (2005).

\section{Results}

\subsection{Comparison with flux observations}

The ETEML model was applied to the SMACEX region using satellite data and regional meteorological data. For a comparison with observations from the tower network, the estimated fluxes were averaged over the estimated upwind source-area (1-2 pixels) for each flux tower (Choi et al., 2009; Gonzalez-Dugo et al., 2009; McCabe \& Wood, 2006). Comparisons between energy balance components $\left(R_{n}, G, L E\right.$, and $\mathrm{H}$ ), estimated by ETEML at the time of the Landsat overpass, and those from tower-based measurements, are shown in Fig. 3 and Table 1. In general, the estimated four energy balance components show a good agreement with tower-based measurements. Model biases 


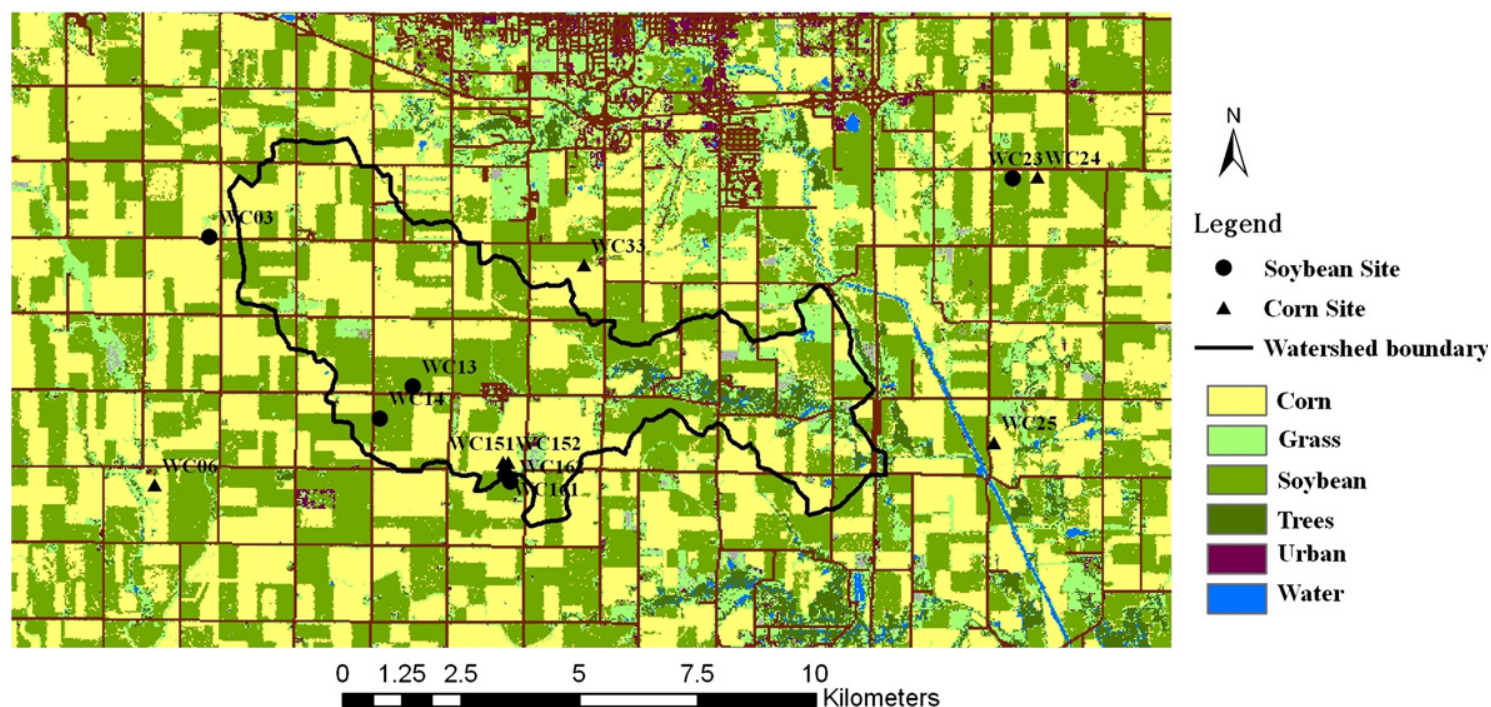

Fig. 2. The distribution of flux towers in the Walnut Creek catchment and the land use classifications.

in estimated $R_{n}$ and $G$ were less than $10 \mathrm{~W} / \mathrm{m}^{2}$. The averaged $H$ of tower-based measurements is $131 \mathrm{~W} / \mathrm{m}^{2}$, while the averaged $\mathrm{H}$ estimates is $161 \mathrm{~W} / \mathrm{m}^{2}$. The bias is $30 \mathrm{~W} / \mathrm{m}^{2}$. The ETEML seems to have slightly overestimated the sensible heat flux. The MAD and RMSD for the estimated $\mathrm{H}$ are $44 \mathrm{~W} / \mathrm{m}^{2}$ and $51 \mathrm{~W} / \mathrm{m}^{2}$, respectively. In ETEML, LE is computed based on the CWSI concept instead of the residual method adopted in many energy balance-based models. The mean LE of tower- based measurements is $389 \mathrm{~W} / \mathrm{m}^{2}$, while the mean LE estimate is $383 \mathrm{~W} / \mathrm{m}^{2}$. The bias is $-6 \mathrm{~W} / \mathrm{m}^{2}$. The MAD and RMSD for the estimated LE are, respectively, $49 \mathrm{~W} / \mathrm{m}^{2}$ and $59 \mathrm{~W} / \mathrm{m}^{2}$.

In comparison with ETEML, the simpler TIM1 and TIM2 versions of the trapezoid interpolation model perform poorly in application to this dataset. While modeled $\mathrm{R}_{\mathrm{n}}$ and $\mathrm{G}$ values are reasonable, TIM1 significantly overestimates $\mathrm{H}$ and underestimates LE (Table 1 and Fig. 3).
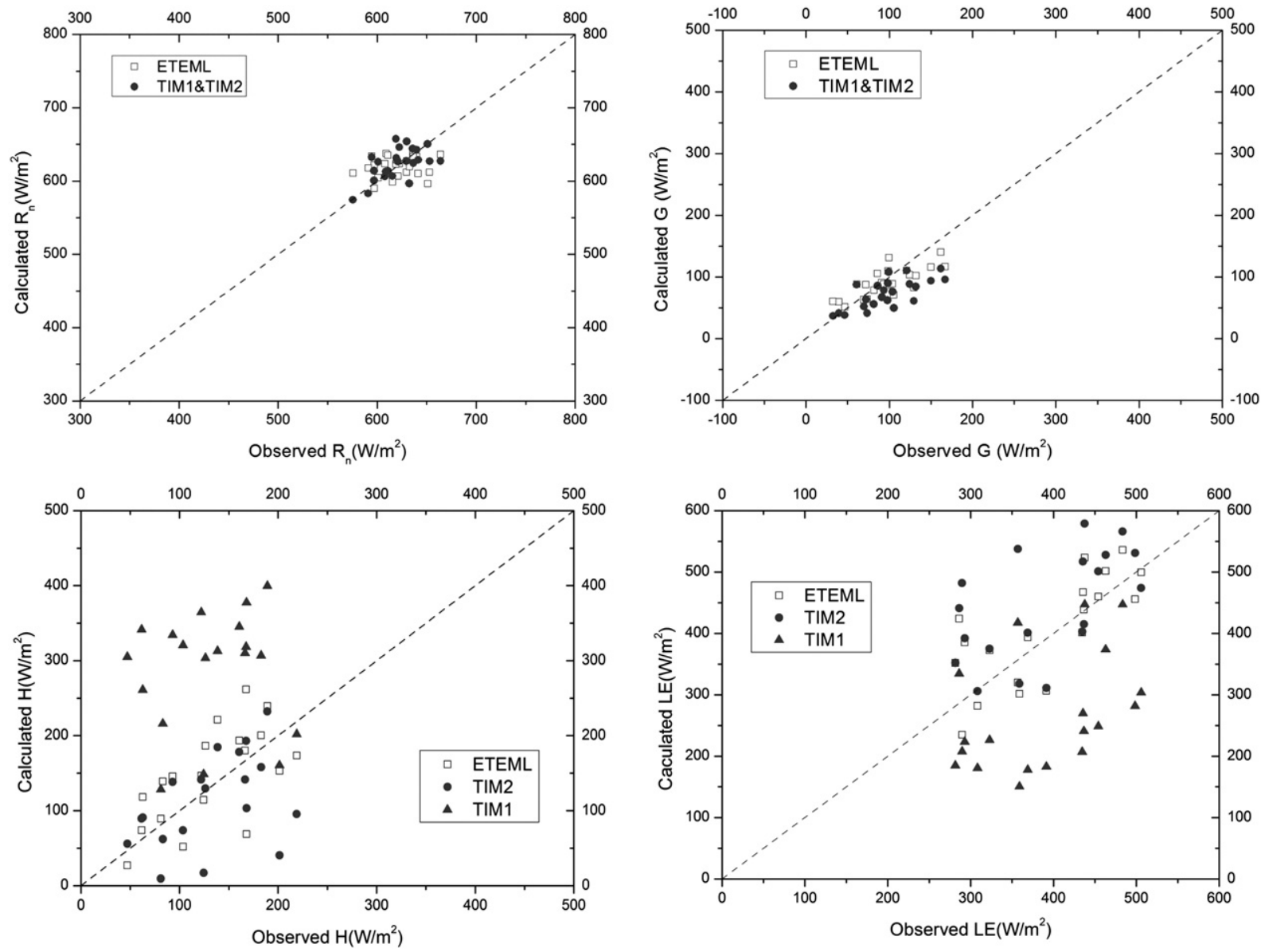

Fig. 3. Comparison between modeled and measured energy fluxes at the Landsat overpass time on DOY 174 and 182 of 2002. 
Table 1

Statistics comparing modeled output and flux measurements $\left(\mathrm{W} / \mathrm{m}^{2}\right)$.

\begin{tabular}{|c|c|c|c|c|c|c|c|c|c|c|c|c|c|}
\hline \multirow[t]{2}{*}{ Flux component } & \multirow[t]{2}{*}{ Observed average } & \multicolumn{4}{|l|}{ ETEML } & \multicolumn{4}{|l|}{ TIM2 } & \multicolumn{4}{|l|}{ TIM1 } \\
\hline & & Average & BIAS & MAD & RMSD & Average & BIAS & MAD & RMSD & Average & BIAS & MAD & RMSD \\
\hline $\mathrm{Rn}$ & 616 & 619 & 3 & 18 & 23 & 623 & 7 & 14 & 19 & 623 & 7 & 14 & 19 \\
\hline G & 97 & 90 & -7 & 19 & 23 & 72 & -25 & 27 & 34 & 72 & -25 & 27 & 34 \\
\hline $\mathrm{H}$ & 131 & 161 & 30 & 44 & 51 & 124 & -7 & 47 & 62 & 294 & 163 & 161 & 179 \\
\hline LE & 389 & 383 & -6 & 49 & 59 & 425 & 36 & 75 & 92 & 255 & -134 & 133 & 150 \\
\hline
\end{tabular}

TIM2 performs better, but is still shown to overestimate LE (Table 1 and Fig. 3).

In summary, ETEML, TIM1, and TIM2 performed similarly in comparison with $R_{n}$ and $G$ observations. TIM1 produces large errors in estimating $\mathrm{H}$ and LE. TIM2 shows improved performance on $\mathrm{H}$ and LE estimates compared to TIM1. ETEML shows the best performance among the three models, indicated by the model performance statistics in Table 1.

\subsection{Spatial distribution of estimated LE}

The spatial and frequency distribution of the LE estimated by ETEML, TIM1, and TIM2 based on the Landsat-derived variables are shown in Figs. 4 and 5. The statistics for LE estimates are listed in Table 2. The spatial patterns produced by the contrast between soybean and corn fields are clear in the ETEML- and TIM2-derived LE map. However, this contrast is less significant in the LE estimate derived by TIM1. In DOY 174, both ETEML- and TIM2-based LE show clear bimodal separation of flux patterns. However, only one peak was observed in the TIM1based LE estimate. The LE values estimated by TIM1 are obviously less than those derived by TIM2 and ETEML. In DOY 182, the spatial patterns derived from TIM2 and ETEML are similar. However, the TIM2-based LE estimates of corn filed are larger than the ETEML-based LE estimates. The frequency distribution of TIM1- and TIM2-based estimates shows a bimodal feature. However, a multimodal feature is observed in ETEML-based LE in DOY 182. Comparing the mean values listed in Table 2, the ETEML-based LE is larger than that of the TIM1-based and less than that of the TIM2-based LE. The standard deviation values are also listed in Table 2, and the ETEML-based values are larger than TIM1-based and TIM2-based values, which indicate a higher spatial variability of ETEML-based LE estimates.

The spatial distribution of soil evaporation and vegetation transpiration of the study area derived by ETEML is shown in Fig. 6. The transpiration rate in corn fields is larger than that in soybean fields because the corn fields have higher LAI values than the soybean fields; the difference between the two is approximately $120 \mathrm{~W} / \mathrm{m}^{2}$. The soil evaporation is relatively small compared to the vegetation transpiration, and the value is less than $220 \mathrm{~W} / \mathrm{m}^{2}$. The derived vegetation transpiration and soil evaporation are comparable to other published studies by Anderson et al. (2005) and Yang and Shang (2013).
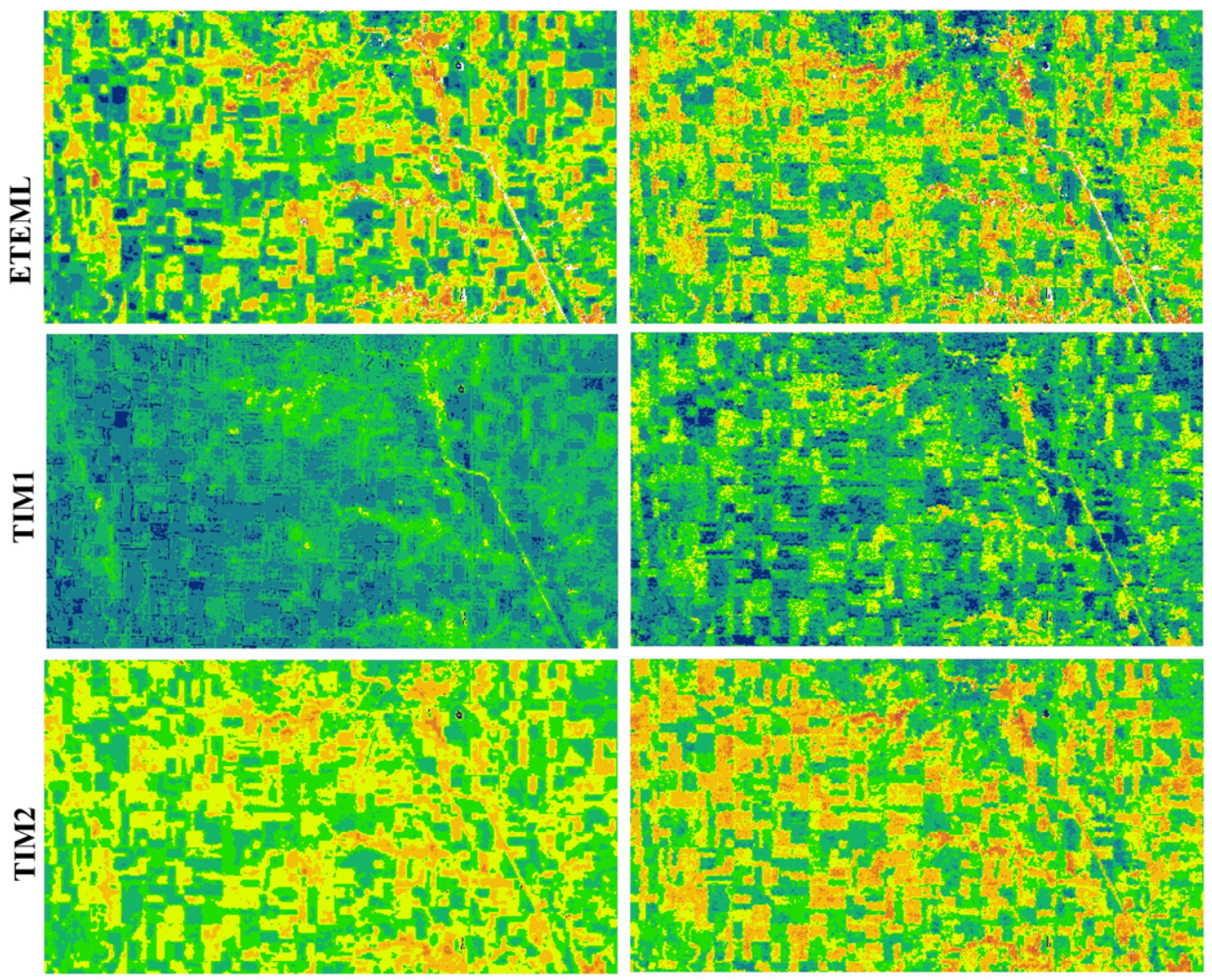

DOY174

$\mathbf{L E}\left(\mathbf{W} / \mathrm{m}^{2}\right)$

DOY182

Fig. 4. The spatial distribution of LE over SMACEX region based on ETEML, TIM1, and TIM2 from Landsat-based variables on DOY 174 and 182. 

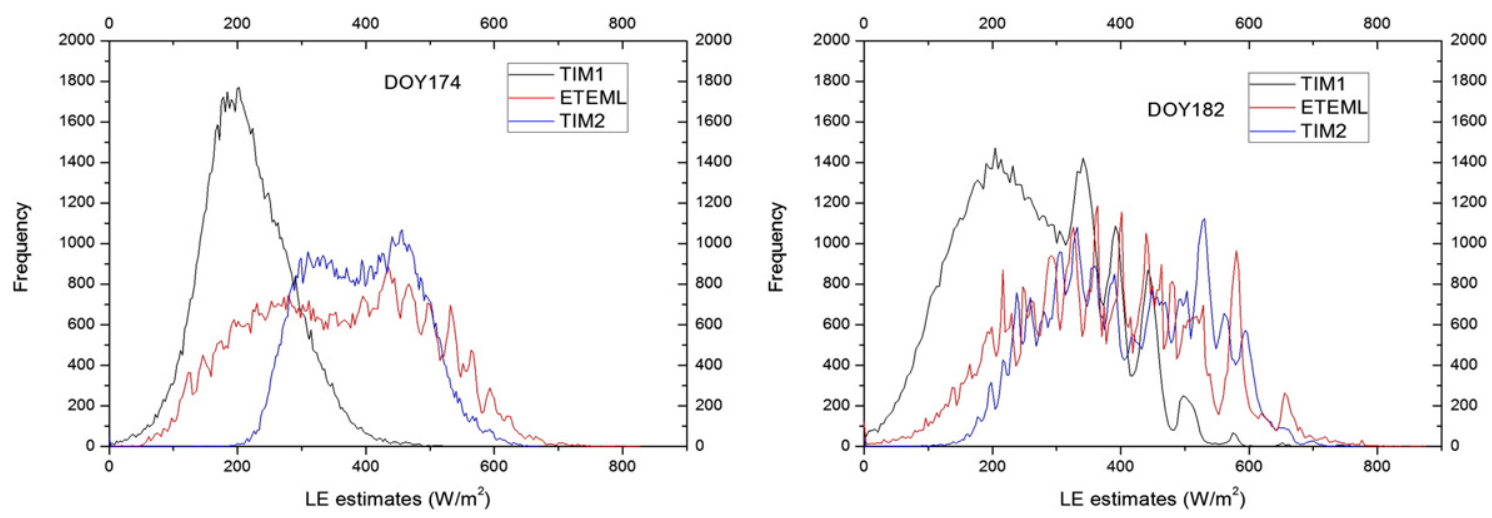

Fig. 5. The frequency distribution of LE from ETEML, TIM1, and TIM2 based on Landsat-derived variables on DOY 174 and 182.

\subsection{Model inter-comparison and the implications from the VFC/LST trape- zoid space}

A spatial (pixel-by-pixel) inter-comparison of latent heat flux generated by ETEML, TIM1, and TIM2 was conducted. Fig. 7 shows scatter plots of the latent heat flux derived from TIM1 and TIM2 against that derived from ETEML. The LE derived from TIM1 is mostly lower than that derived from ETEML. For TIM2, the LE estimates are close to ETEMLbased estimates. However, LE estimates for soybean fields derived from TIM2 are larger than those derived from ETEML. The discrepancy among the three models may be attributed to the determination of the VFC/LST trapezoid space.

Different strategies for the determination of the VFC/LST trapezoid space are responsible for the large differences among the three modeling approaches. Fig. 8 shows the trapezoid space determined for TIM1 (the blue lines) and TIM2 (the dark lines) on DOY 182. All pixels are being bounded with a single trapezoid space in TIM1 and TIM2. However, this strategy may not be reasonable. The theoretical trapezoid spaces for five random pixels, three from the corn field and two from the soybean field, are determined using ETEML. The theoretical trapezoid space for each pixel and the location of each pixel are plotted in Fig. 8. It is clear that the trapezoid spaces are not coincidental with each other, and the different trapezoid spaces are highly dependent on the vegetation covers. Furthermore, each pixel has its own trapezoid space, and it seems almost impossible to find a universal dry edge and wet edge for all pixels. Therefore, the determined dry edge and wet edge in TIM1 and TIM2 are not reasonable and cannot be used to represent the real boundary conditions for all pixels.

Moreover, the assumptions involved in the VFC/LST trapezoid space are not satisfied in TIM1 and TIM2. The assumption that the isoline or the mixed surface temperature in the VFC/LSF trapezoid space is mainly controlled by soil water availability has to be satisfied. LST is controlled by energy balance and radiation budget equations (Long \& Singh, 2012; Yang \& Shang, 2013; Zhang, 2009; Zhang et al., 2008). If the impact of

Table 2

Statistics for regional-scale latent heat flux $\left(\mathrm{W} / \mathrm{m}^{2}\right)$.

\begin{tabular}{|c|c|c|c|c|c|}
\hline & & \multicolumn{2}{|c|}{ DOY 174} & \multicolumn{2}{|c|}{ DOY 182} \\
\hline & & Mean & Standard deviation & Mean & Standard deviation \\
\hline \multirow[t]{3}{*}{ ETEML } & Regional & 360 & 135 & 377 & 139 \\
\hline & Corn & 482 & 144 & 502 & 150 \\
\hline & Soybean & 271 & 106 & 308 & 108 \\
\hline \multirow[t]{3}{*}{ TIM1 } & Regional & 216 & 69 & 264 & 111 \\
\hline & Corn & 258 & 78 & 381 & 114 \\
\hline & Soybean & 183 & 50 & 188 & 76 \\
\hline \multirow[t]{3}{*}{ TIM2 } & Regional & 397 & 83 & 408 & 120 \\
\hline & Corn & 513 & 102 & 576 & 128 \\
\hline & Soybean & 333 & 60 & 321 & 79 \\
\hline
\end{tabular}

other controlling factors (air temperature, albedo, water vapor pressure, and aerodynamic resistance) on LST is not negligible, the derivation of evaporation from TIM1 and TIM2 would definitely involve uncertainties. To clearly illustrate this problem, two 3D scatter plots are plotted in Fig. 9. In Fig. 9(a), the 3D space comprises the VFC (X axis), LST (Y axis), and albedo ( $Z$ axis) from Landsat-based variables on DOY 182. Every point is located in the 3D space with its VFC, LST, and albedo values. The projection of points on the $\mathrm{X}-\mathrm{Y}$ plane is just the VFC/LST trapezoid space used in TIM1 and TIM2. It is clear that the albedo for pixels has a large variation, ranging from 0.14 to 0.25 . This will lead to a difference of about $11 \%$ on net radiation, and therefore, it will introduce large uncertainties in the ET estimates. A similar scatter plot for VFC, LST, and crop height is plotted in Fig. 9(b). It is revealed that the crop height has a large variance for the pixels, although they have the same VFC value in the trapezoid space. To summarize, because of the uncertainties involved in TIM1 and TIM2, the TIMs-derived LE estimates are less reliable. However, the assumption involved in the trapezoid space is fully satisfied in ETEML. In the theoretical VFC/LST trapezoid space, the four extreme points are estimated using a simple land surface model, and the variations of ( LST- $_{\mathrm{a}}$ ) in the vertical direction in the trapezoid space are only linearly associated with variations in evapotranspiration or water availability. The physical basis of the trapezoid framework-based ET modeling approaches is strengthened.

\section{Discussion}

\subsection{Advantages of ETEML}

In realizing the disadvantages of TIMs, an enhanced two-source ET model is proposed. The advantages of ETEML lie in the following three aspects: (1) The ETEML can expand the applications of TIMs to heterogeneous surfaces. Traditionally, traditional TIMs are only applicable to homogeneous surfaces (Carlson, 2007; Petropoulos et al., 2009; Zhang, 2009). Moreover, a recent study from Tian et al. (2013) indicated that the variation of the spatial domain size would directly lead to the deviation of ET estimates. This created difficulty for traditional TIMs to couple with other pixel-based models. In ETEML, the theoretical VFC/LST trapezoid space is determined for each pixel, and the application of the model is not restricted to homogeneous surfaces. (2) In ETEML, a physical pixel-based surface temperature decomposition method is presented based on the theoretical VFC/LST trapezoid space. With the newly defined theoretical VFC/LST trapezoid space, the assumptions involved in the VFC/LST trapezoid space are fully satisfied, and the subjectivity and uncertainties related to the determination of the trapezoid space are greatly reduced. With these improvements, ETEML greatly overcomes the empirical and uncertain nature related to traditional TIMs. (3) ETEML is based on a two-source scheme, and the soil evaporation and vegetation transpiration can be derived separately. ETEML directly uses the component temperatures to calculate the component 


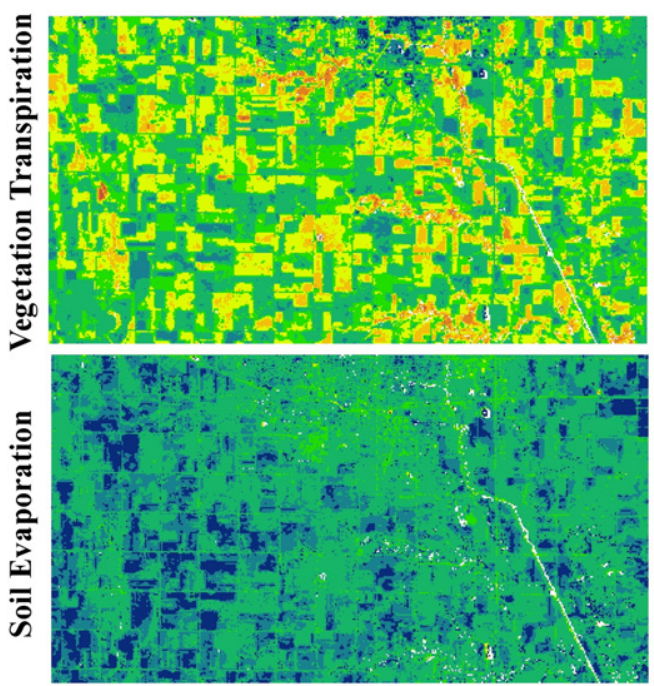

DOY174

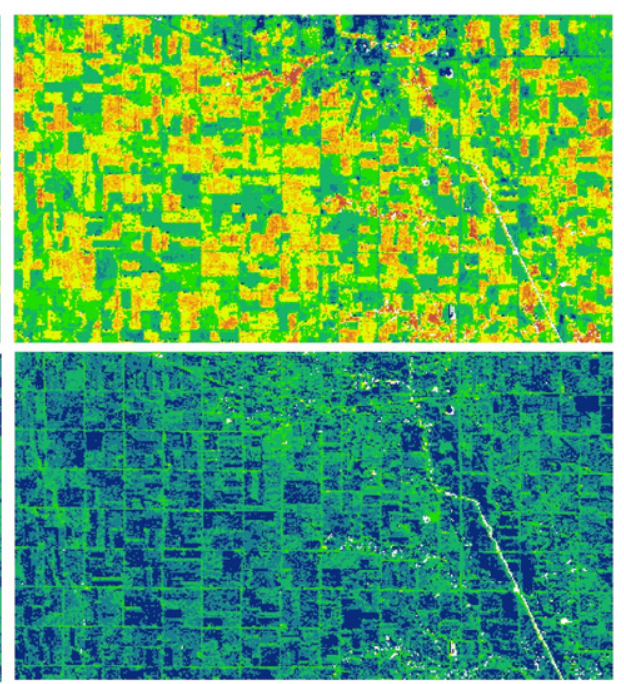

DOY182

$\operatorname{LE}\left(\mathbf{W} / \mathbf{m}^{2}\right)$

Fig. 6. The spatial distribution of vegetation transpiration and soil evaporation of the SMACEX region based on ETEML from Landsat-based variables on DOY 174 and 182.

fluxes, and this deviates from TSEB, which uses an iterative approach to derive a physical solution.

\subsection{Comparison with other models}

By evaluating the ETEML using the SMACEX data, the performance of ETEML is found to be comparable to other published studies. Kalma et al. (2008) reviewed 30 published articles on remote sensing-based ET models, and the assessment indicates an average root square error value of about $50 \mathrm{~W} / \mathrm{m}^{2}$ and relative errors of $15-30 \%$. The SMACEX data have been widely used to validate and evaluate the ET models (Anderson et al., 2005; Cammalleri, Anderson, Gao, Hain, \& Kustas, 2013; Chavez, Neale, Hipps, Prueger, \& Kustas, 2005; Choi et al., 2009; French et al., 2005; Gonzalez-Dugo et al., 2009; Kustas et al., 2004; Li et al., 2005, 2006; Long \& Singh, 2012; Su et al., 2005; Yang \& Shang, 2013). Long and Singh (2012) and Yang and Shang (2013) collected
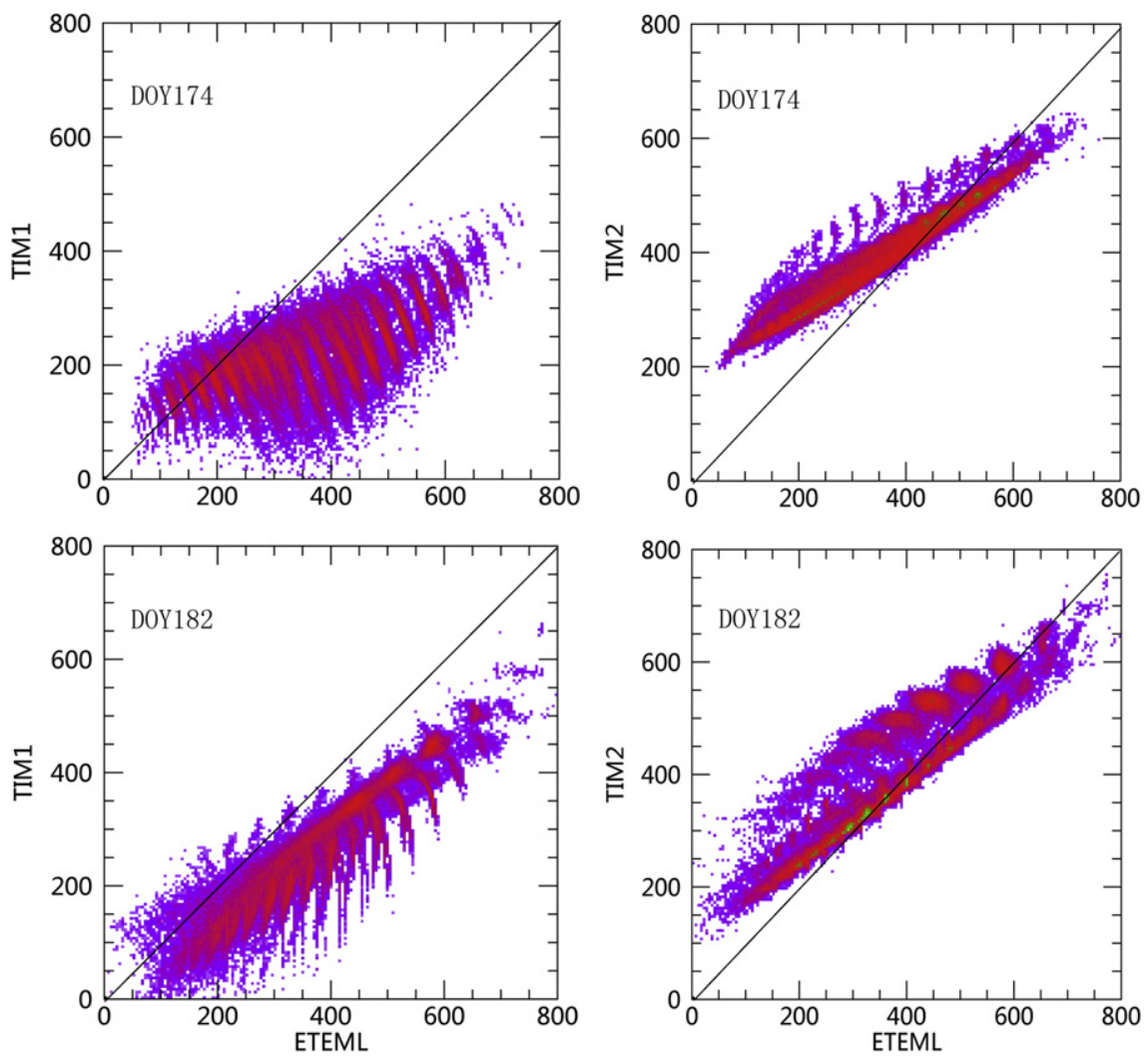

Fig. 7. ETEML predicted latent heat flux $\left(\mathrm{W} / \mathrm{m}^{2}\right)$ versus TIM1 and TIM2 predicted latent heat flux of the SMACEX region from Landsat-based variables on DOY 174 and 182. 


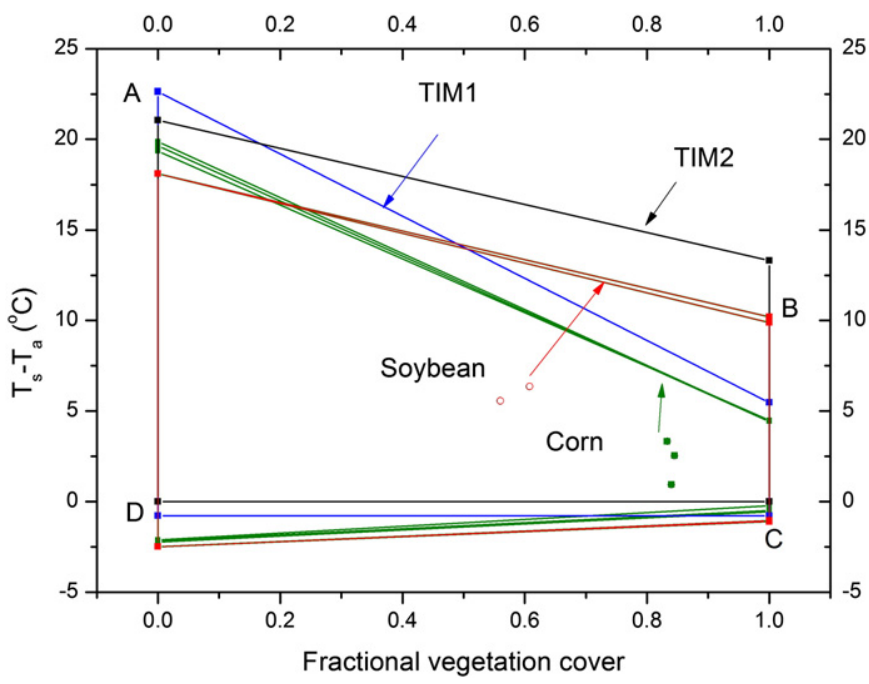

Fig. 8. The trapezoid space determined in TIM1, TIM2, and ETEML on DOY 182. The blue lines represent the dry and wet edges used in TIM1. The dark lines represent the trapezoid space applied in TIM2. The red and olive lines represent the theoretical trapezoid space determined for two soybean pixels and three corn pixels randomly selected from the satellite image using ETEML

the statistics of the discrepancies between surface flux retrievals and flux tower measurements from published studies (Table 4 in Long and Singh (2012); Fig. 10 and Table 3 in Yang and Shang (2013)). In this study, the bias and RMSD of LE estimates based on ETEML are $-6 \mathrm{~W} / \mathrm{m}^{2}$ and $59 \mathrm{~W} / \mathrm{m}^{2}$, respectively. The bias and RMSD of $\mathrm{H}$ estimates from ETEML are $30 \mathrm{~W} / \mathrm{m}^{2}$ and $51 \mathrm{~W} / \mathrm{m}^{2}$, respectively. The statistics of ETEML are within the range of the other published studies, and the performance of ETEML is acceptable.

\subsection{Further thoughts on ETEML}

Currently, like most other thermal remote-sensing ET models, the ETEML provides instantaneous ET estimates at the time of the satellite overpass, whereas most applications in irrigation and hydrology require ET estimates over daily or longer time periods. This requires extrapolation from instantaneous values to daily or longer time steps. The evaporative fraction method and the referenced ET-based extrapolation fraction method are widely used to derive daily ET (Allen, Tasumi, Morse, et al., 2007; Allen, Tasumi and Trezza, 2007; Brutsaert \& Chen, 1996; Brutsaert \& Sugita, 1992; Chavez, Neale, Prueger, \& Kustas, 2008; Colaizzi, Evett, Howell, \& Tolk, 2006; Crago, 1996). Due to the low availability of quality satellite images, developing a reliable method for extrapolating daily values to longer time scales is imperative.
Recently, Van Niel et al. (2011) carefully studied the evaporative fraction method and proposed a generic correction method to reduce bias in daily ET estimates. For monthly scale, Van Niel et al. (2012) evaluated the accuracy of four upscaling approaches with site observations and proposed a simple procedure to minimize the upscaling bias. Furthermore, data fusion will definitely add value to seasonal ET assessment. Cammalleri et al. (2013) proposed a data fusion approach on use of MODIS- and Landsat-derived ET maps to obtain daily and seasonal ET. These works provide an insightful reference. Our ongoing work will focus on expansion of the ETEML to derive daily or longer time scale ET.

Regionally gridded meteorological variables are required for the regional application of ETEML. The representativeness of the in situ data is often limited to the footprint of the site. This could be resolved by incorporating the reanalysis metrological data from the data assimilation system. NASA Global Modeling and Assimilation Office's (GMAO) Modern Era Retrospective Analysis for Research and Applications (MERRA; Rienecker et al., 2011) uses data from all available global surface weather observations every $3 \mathrm{~h}$, and GEOS-5 was used to interpolate and grid these point data on a short time sequence, thus producing an estimate of climatic conditions for the world, at $10 \mathrm{~m}$ above the land surface and at a resolution of $0.5^{\circ}$ latitude by $0.6^{\circ}$ longitude. Detailed information on the MERRA dataset is available at the Web site (http://gmao. gsfc.nasa.gov/research/merra/). This data have been used in developing Global ET products by Mu et al. (2007). The Global Land Data Assimilation System (GLDAS; Rodell et al., 2004) has mapped climatological values for the land surface. One good example is Su, Wood, McCabe, and Su (2007), who evaluated the SEBS model based on MODIS and GLDAS forcing data over the CEOP EOP-1 reference site. These data sources would make it possible to apply ETEML to larger spatial domains in the near future.

\section{Conclusion}

In this study, a physically based two-source model (ETEML) is proposed based on the trapezoid framework of the VFC/LST space. In ETEML, a theoretical VFC/LST trapezoid space is defined for each pixel, and a pixel-wise-mixed-surface temperature decomposition method is presented. Using the derived component temperatures, soil evaporation and vegetation transpiration are separately parameterized using the CWSI concept in the newly developed model. With these improvements, ETEML removes the restriction in the application of conventional TIMs. ETEML can be used to separate the soil evaporation and vegetation transpiration in heterogeneous covered area.

To evaluate the performance of ETEML, the model was applied to the SMACEX with a remotely sensed dataset at a regional scale. Compared with tower observations, the MAD and RMSD for the ETEML estimated LE are $49 \mathrm{~W} / \mathrm{m}^{2}$ and $59 \mathrm{~W} / \mathrm{m}^{2}$, respectively. A further inter-comparison between TIM1, TIM2, and ETEML indicate that ETEML reduces the subjectivity and uncertainties associated with TIM1 and TIM2. In addition, the
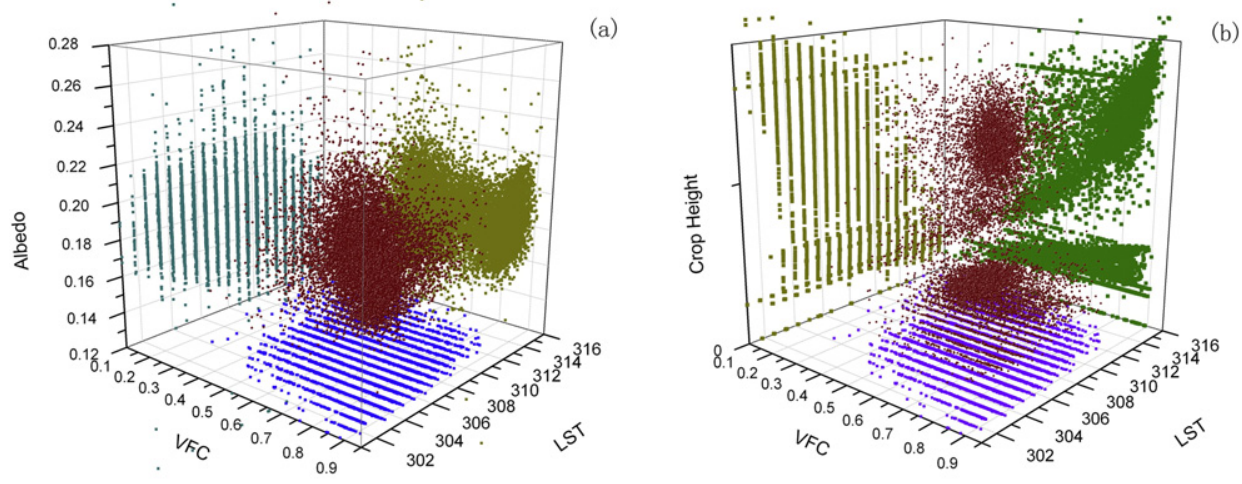

Fig. 9. 3D Scatter Plots (a) composed of VFC (X axis), LST (Y axis), and albedo ( $Z$ axis); (b) composed of VFC (X axis), LST (Y axis), and crop height (Z axis). 
performance of ETEML is comparable to other published studies. Overall, the results suggest that ETEML is promising and can be used to expand the applications of the trapezoid framework-based ET modeling approaches to heterogeneous surfaces.

\section{Acknowledgments}

The authors are very thankful to the researchers in SMACEX data acquisition and sharing. This work is supported jointly by the Project of Natural Science Fund of China (41171286), the National High Technology Research and Development Program (2012AA12A309), and the "948" plan of Ministry of Water Resources of the P.R. China (1401), the Knowledge Innovation Program (KZCX2-YW-326-1) and the High Resolution Earth Observation System Program of China (no. 08Y30B07-9001-13/15).

\section{References}

Allen, R. G., Pereira, L. S., Raes, D., \& Smith, M. (1998). Crop evapotranspiration - Guidelines for computing crop water requirements. FAO Irrigation and Drainage Paper, 56. (pp. 300). Rome: FAO.

Allen, R. G., Tasumi, M., Morse, A., Trezza, R., Wright, J. L., Bastiaanssen, W., et al. (2007) Satellite-based energy balance for mapping evapotranspiration with internalized calibration (METRIC) - Applications. Journal of Irrigation and Drainage Engineering-ASCE, 133, 395-406.

Allen, R. G., Tasumi, M., \& Trezza, R. (2007). Satellite-based energy balance for mapping evapotranspiration with internalized calibration (METRIC) - Model. Journal of Irrigation and Drainage Engineering-ASCE, 133, 380-394.

Anderson, M. C., Neale, C. M. U., Li, F., Norman, J. M., Kustas, W. P., Jayanthi, H., et al. (2004). Upscaling ground observations of vegetation water content, canopy height, and leaf area index during SMEX02 using aircraft and Landsat imagery. Remote Sensing of Environment, 92, 447-464.

Anderson, M. C., Norman, J. M., Kustas, W. P., Li, F. Q., Prueger, J. H., \& Mecikalski, J. R. (2005). Effects of vegetation clumping on two-source model estimates of surface energy fluxes from an agricultural landscape during SMACEX. Journal of Hydrometeorology, 6 , 892-909.

Anderson, M. C., Norman, J. M., Mecikalski, J. R., Otkin, J. A., \& Kustas, W. P. (2007a). A climatological study of evapotranspiration and moisture stress across the continental United States based on thermal remote sensing: 1. Model formulation. Journal of Geophysical Research-Atmospheres, 112, 1-17.

Anderson, M. C., Norman, J. M., Mecikalski, J. R., Otkin, J. A., \& Kustas, W. P. (2007b). A climatological study of evapotranspiration and moisture stress across the continental United States based on thermal remote sensing: 2. Surface moisture climatology. Journal of Geophysical Research-Atmospheres, 112, 1-13.

Bastiaanssen, W. G. M., Menenti, M., Feddes, R. A., \& Holtslag, A. A. M. (1998). A remote sensing surface energy balance algorithm for land (SEBAL). 1. Formulation. Journal of Hydrology, 212, 198-212.

Bastiaanssen, W. G. M., Pelgrum, H., Wang, J., Ma, Y., Moreno, J. F., Roerink, G. J., et al. (1998). A remote sensing surface energy balance algorithm for land (SEBAL).: Part 2: Validation. Journal of Hydrology, 212, 213-229.

Brutsaert, W. (1982). Evaporation into the atmosphere: Theory, history, and applications. New York: Springer.

Brutsaert, W. (2005). Hydrology: An introduction. New York: Cambridge Univ Press.

Brutsaert, W., \& Chen, D. (1996). Diurnal variation of surface fluxes during thorough drying (or severe drought) of natural prairie. Water Resources Research, 32, 2013-2019.

Brutsaert, W., \& Sugita, M. (1992). Application of self-preservation in the diurnal evolution of the surface energy budget to determine daily evaporation. Journal of Geophysical Research: Atmospheres (1984-2012), 97, 18377-18382.

Cammalleri, C., Anderson, M. C., Gao, F., Hain, C. R., \& Kustas, W. P. (2013). A data fusion approach for mapping daily evapotranspiration at field scale. Water Resources Research, 49, 4672-4686.

Campbell, G. S., \& Norman, J. M. (1998). An introduction to environmental biophysics (2nd edition ). New York: Springer.

Carlson, T. (2007). An overview of the "triangle method" for estimating surface evapotranspiration and soil moisture from satellite imagery. Sensors, 7, 1612-1629.

Chavez, J. L., Neale, C. M. U., Hipps, L. E., Prueger, J. H., \& Kustas, W. P. (2005). Comparing aircraft-based remotely sensed energy balance fluxes with eddy covariance tower data using heat flux source area functions. Journal of Hydrometeorology, 6, 923-940.

Chavez, J. L., Neale, C. M., Prueger, J. H., \& Kustas, W. P. (2008). Daily evapotranspiration estimates from extrapolating instantaneous airborne remote sensing ET values. Irrigation Science, 27, 67-81.

Choi, M., Kustas, W. P., Anderson, M. C., Allen, R. G., Li, F. Q., \& Kjaersgaard, J. H. (2009). An intercomparison of three remote sensing-based surface energy balance algorithms over a corn and soybean production region (Iowa, US) during SMACEX. Agricultural and Forest Meteorology, 149, 2082-2097.

Choudhury, B. J., Idso, S. B., \& Reginato, R. J. (1987). Analysis of an empirical model for soil heat flux under a growing wheat crop for estimating evaporation by an infraredtemperature based energy balance equation. Agricultural and Forest Meteorology, 39, 283-297.
Colaizzi, P. D., Evett, S. R., Howell, T. A., \& Tolk, J. A. (2006). Comparison of five models to scale daily evapotranspiration from one-time-of-day measurements. Transactions of the ASAE, 49, 1409-1417.

Crago, R. D. (1996). Conservation and variability of the evaporative fraction during the daytime. Journal of Hydrology, 180, 173-194.

Eagleson, P. S. (2002). Ecohydrology: Darwinian expression of vegetation form and function. New York: Cambridge Univ. Pr.

Foken, T. (2008). The energy balance closure problem: An overview. Ecological Applications, 18, 1351-1367.

Foken, T., Wimmer, F., Mauder, M., Thomas, C., \& Liebethal, C. (2006). Some aspects of the energy balance closure problem. Atmospheric Chemistry and Physics, 6, 4395-4402.

French, A. N., Jacob, F., Anderson, M. C., Kustas, W. P., Timmermans, W., Gieske, A., et al. (2005). Surface energy fluxes with the. Advanced Spaceborne Thermal Emission and Reflection radiometer (ASTER) at the Iowa 2002 SMACEX site (USA) Remote Sensing of Environment, 99(1-2), 55-65.

Gillies, R. R., Carlson, T. N., Cui, J., Kustas, W. P., \& Humes, K. S. (1997). A verification of the 'triangle' method for obtaining surface soil water content and energy fluxes from remote measurements of the Normalized Difference Vegetation Index (NDVI) and surface radiant temperature. International Journal of Remote Sensing, 18, 3145-3166.

Glenn, E. P., Huete, A. R., Nagler, P. L., Hirschboeck, K. K., \& Brown, P. (2007). Integrating remote sensing and ground methods to estimate evapotranspiration. Critical Reviews in Plant Sciences, 26, 139-168.

Gonzalez-Dugo, M. P., Neale, C. M. U., Mateos, L., Kustas, W. P., Prueger, J. H., Anderson, M. C., et al. (2009). A comparison of operational remote sensing-based models for estimating crop evapotranspiration. Agricultural and Forest Meteorology, 149, 1843-1853.

Jackson, R. D., Idso, S. B., Reginato, R. J., \& Pinter, P. J. (1981). Canopy temperature as a crop water-stress indicator. Water Resources Research, 17, 1133-1138.

Jackson, R. D., Kustas, W. P., \& Choudhury, B. J. (1988). A reexamination of the crop waterstress index. Irrigation Science, 9, 309-317.

Jiang, L., \& Islam, S. (2001). Estimation of surface evaporation map over southern Great Plains using remote sensing data. Water Resources Research, 37, 329-340.

Jiang, L., \& Islam, S. (2003). An intercomparison of regional latent heat flux estimation using remote sensing data. International Journal of Remote Sensing, 24 2221-2236.

Jiménez, C., Prigent, C., Mueller, B., Seneviratne, S., Mc-Cabe, M., Wood, E., et al. (2011). Global intercomparison of 12 land surface heat flux estimates. Journal of Geophysical Research, 116, 1-27.

Kabat, P. (2004). Vegetation, water, humans and the climate: A new perspective on an interactive system. Springer.

Kalma, J. D., McVicar, T. R., \& McCabe, M. F. (2008). Estimating land surface evaporation: A review of methods using remotely sensed surface temperature data. Surveys in Geophysics, 29, 421-469.

Katul, G. G., Oren, R., Manzoni, S., Higgins, C., \& Parlange, M. B. (2012). Evapotranspiration: A process driving mass transport and energy exchange in the soil-plant-atmosphere-climate system. Reviews of Geophysics, 50.

Kustas, W., \& Anderson, M. (2009). Advances in thermal infrared remote sensing for land surface modeling. Agricultural and Forest Meteorology, 149, 2071-2081.

Kustas, W. P., Choudhury, B. J., Moran, M. S., Reginato, R. J., Jackson, R. D., Gay, L. W., et al (1989). Determination of sensible heat flux over sparse canopy using thermal infrared data. Agricultural and Forest Meteorology, 44, 197-216.

Kustas, W. P., Hatfield, J. L., \& Prueger, J. H. (2005). The soil moisture-atmosphere coupling experiment (SMACEX): Background, hydrometeorological conditions, and preliminary findings. Journal of Hydrometeorology, 6, 791-804.

Kustas, W. P., Li, F., Jackson, T. J., Prueger, J. H., MacPherson, J. I., \& Wolde, M. (2004). Effects of remote sensing pixel resolution on modeled energy flux variability of croplands in Iowa. Remote Sensing of Environment, 92, 535-547.

Kustas, W. P., \& Norman, J. M. (2000). A two-source energy balance approach using directional radiometric temperature observations for sparse canopy covered surfaces. Agronomy Journal, 92, 847-854.

Leuning, R., van Gorsel, E., Massman, W. J., \& Isaac, P. R. (2012). Reflections on the surface energy imbalance problem. Agricultural and Forest Meteorology, 156, 65-74.

Li, F., Jackson, T. J., Kustas, W. P., Schmugge, T. J., French, A. N., Cosh, M. H., et al. (2004) Deriving land surface temperature from Landsat 5 and 7 during SMEX02/SMACEX Remote Sensing of Environment, 92, 521-534.

Li, F., Kustas, W. P., Anderson, M. C., Jackson, T. J., Bindlish, R., \& Prueger, J. H. (2006). Comparing the utility of microwave and thermal remote-sensing constraints in twosource energy balance modeling over an agricultural landscape. Remote Sensing of Environment, 101, 315-328.

Li, F. Q., Kustas, W. P., Prueger, J. H., Neale, C. M. U., \& Jackson, T. J. (2005). Utility of remote sensing-based two-source energy balance model under low- and high-vegetation cover conditions. Journal of Hydrometeorology, 6, 878-891.

Li, Z. L., Tang, R., Wan, Z., Bi, Y., Zhou, C., Tang, B., et al. (2009). A review of current methodologies for regional evapotranspiration estimation from remotely sensed data. Sensors, 9, 3801-3853.

Long, D., \& Singh, V. P. (2012). A two-source trapezoid model for evapotranspiration (TTME) from satellite imagery. Remote Sensing of Environment, 121, 370-388.

McCabe, M. F., \& Wood, E. F. (2006). Scale influences on the remote estimation of evapotranspiration using multiple satellite sensors. Remote Sensing of Environment, 105 271-285.

Moran, M. S., Clarke, T. R., Inoue, Y., \& Vidal, A. (1994). Estimating crop water deficit using the relation between surface-air temperature and spectral vegetation index. Remote Sensing of Environment, 49, 246-263.

Moran, M. S., Rahman, A. F., Washburne, J. C., Goodrich, D. C., Weltz, M. A., \& Kustas, W. P. (1996). Combining the Penman-Monteith equation with measurements of surface temperature and reflectance to estimate evaporation rates of semiarid grassland. Agricultural and Forest Meteorology, 80, 87-109. 
Mu, Q., Heinsch, F. A., Zhao, M., \& Running, S. W. (2007). Development of a global evapotranspiration algorithm based on MODIS and global meteorology data. Remote Sensing of Enviromment, 111, 519-536.

Mu, Q. Z., Zhao, M. S., \& Running, S. W. (2011). Improvements to a MODIS global terrestrial evapotranspiration algorithm. Remote Sensing of Environment, 115, 1781-1800.

Mueller, B., Hirschi, M., Jimenez, C., Ciais, P., Dirmeyer, P. A., Dolman, A. J., et al. (2013). Benchmark products for land evapotranspiration: LandFlux-EVAL multi-data set synthesis. Hydrology and Earth System Sciences, 17, 3707-3720.

Mueller, B., Seneviratne, S., Jimenez, C., Corti, T., Hirschi, M., Balsamo, G., et al. (2011) Evaluation of global observations-based evapotranspiration datasets and IPCC AR4 simulations. Geophysical Research Letters, 38, 1-7.

Norman, J. M., Kustas, W. P., \& Humes, K. S. (1995). Source approach for estimating soil and vegetation energy fluxes in observations of directional radiometric surfacetemperature. Agricultural and Forest Meteorology, 77, 263-293.

Petropoulos, G. Carlson, T. N. Wooster, M. J. \& Islam, S. (2009). A review of T-s/VI remote sensing based methods for the retrieval of land surface energy fluxes and soil surface moisture. Progress in Physical Geography, 33, 224-250.

Priestley, C., \& Taylor, R. (1972). On the assessment of surface heat flux and evaporation using large-scale parameters. Monthly Weather Review, 100, 81-92.

Prueger, J. H., Hatfield, J. L., Kustas, W. P., Hipps, L. E., MacPherson, J. I., Neale, C. M. U., et al. (2005). Tower and aircraft eddy covariance measurements of water vapor, energy, and carbon dioxide fluxes during SMACEX. Journal of Hydrometeorology, 6, 954-960.

Rienecker, M. M., Suarez, M. J., Gelaro, R., Todling, R., Bacmeister, J., Liu, E., et al. (2011). MERRA: NASA's modern-era retrospective analysis for research and applications. Journal of Climate, 24, 3624-3648.

Rodell, M., Houser, P. R., Jambor, U. E. A., Gottschalck, J., Mitchell, K., Meng, C. J., et al. (2004). The global land data assimilation system. Bulletin of the American Meteorological Society, 85, 381-394.

Sanchez, J. M., Kustas, W. P., Caselles, V. \& Anderson, M. C. (2008). Modelling surface energy fluxes over maize using a two-source patch model and radiometric soil and canopy temperature observations. Remote Sensing of Environment, 112, 1130-1143.

Sandholt, I., Rasmussen, K., \& Andersen, J. (2002). A simple interpretation of the surface temperature/vegetation index space for assessment of surface moisture status. Remote Sensing of Environment, 79, 213-224.

Sellers, P. J., Dickinson, R. E., Randall, D. A., Betts, A. K., Hall, F. G., Berry, J. A., et al. (1997). Modeling the exchanges of energy, water, and carbon between continents and the atmosphere. Science, 275, 502.

Shu, Y. Q., Stisen, S., Jensen, K. H., \& Sandholt, I. (2011). Estimation of regional evapotranspiration over the North China Plain using geostationary satellite data. International Journal of Applied Earth Observation and Geoinformation, 13, 192-206.

Shuttleworth, W. J. (2007). Putting the 'vap' into evaporation. Hydrology and Earth System Sciences, 11, 210-244.

Stisen, S., Sandholt, I., Norgaard, A., Fensholt, R., \& Jensen, K. H. (2008). Combining the triangle method with thermal inertia to estimate regional evapotranspiration - Applied to MSG-SEVIRI data in the Senegal River basin. Remote Sensing of Environment, 112, 1242-1255.

Su, H. B., McCabe, M. F., Wood, E. F., Su, Z., \& Prueger, J. H. (2005). Modeling evapotranspiration during SMACEX: Comparing two approaches for local- and regional-scale prediction. Journal of Hydrometeorology, 6, 910-922.
Su, H., Wood, E. F., McCabe, M. F., \& Su, Z. (2007). Evaluation of remotely sensed evapotranspiration over the CEOP EOP-1 reference sites. Journal of the Meteorological Society of Japan, 85, 439-459.

Tang, R. L., Li, Z. L., \& Tang, B. H. (2010). An application of the T-s-VI triangle method with enhanced edges determination for evapotranspiration estimation from MODIS data in and semi-arid regions: Implementation and validation. Remote Sensing of Environment, 114, 540-551.

Tasumi, M. Allen, R. G \& \& Trezza, R (2008). At-surface reflectance and albedo from satellite for operational calculation of land surface energy balance. Journal of Hydrologic Engineering, 13, 51-63.

Tian, J., Su, H. B., Sun, X. M., Chen, S. H., He, H. L., \& Zhao, L. J. (2013). Impact of the spatial domain size on the performance of the T-s-VI triangle method in terrestrial evapotranspiration estimation. Remote Sensing, 5, 1998-2013.

Timmermans, W. J., Kustas, W. P., Anderson, M. C., \& French, A. N. (2007). An intercomparison of the surface energy balance algorithm for land (SEBAL) and the twosource energy balance (TSEB) modeling schemes. Remote Sensing of Environment, 108, 369-384.

Twine, T. E., Kustas, W. P., Norman, J. M., Cook, D. R., Houser, P. R., Meyers, T. P., et al. (2000). Correcting eddy-covariance flux underestimates over a grassland. Agricultural and Forest Meteorology, 103, 279-300.

Van Niel, T. G., McVicar, T. R., Roderick, M. L., van Dijk, A. I. J. M., Beringer, J., Hutley, L. B., et al. (2012). Upscaling latent heat flux for thermal remote sensing studies: Comparison of alternative approaches and correction of bias. Journal of Hydrology, 468-469, 35-46.

Van Niel, T. G., McVicar, T. R., Roderick, M. L., van Dijk, A. I. J. M., Renzullo, L. J., \& van Gorsel, E. (2011). Correcting for systematic error in satellite-derived latent heat flux due to assumptions in temporal scaling: Assessment from flux tower observations. Journal of Hydrology, 409, 140-148.

Wang, K. C. \& Dickinson, R. E. (2012). A review of global terrestrial evapotranspiration: Observation, modeling, climatology, and climatic variability. Reviews of Geophysics, 50.

Wang, K. C., Li, Z. Q., \& Cribb, M. (2006). Estimation of evaporative fraction from a combination of day and night land surface temperatures and NDVI: A new method to determine the Priestley-Taylor parameter. Remote Sensing of Environment, 102, 293-305.

Yang, Y. T., \& Shang, S. H. (2013). A hybrid dual-source scheme and trapezoid frameworkbased evapotranspiration model (HTEM) using satellite images: Algorithm and model test. Journal of Geophysical Research-Atmospheres, 118, 2284-2300.

Zhang, R. H. (2009). Experimental remote sensing modeling and surface foundations. Beijing: Sciences Press (in Chinese).

Zhang, Y. Q., Leuning, R., Chiew, F. H. S., Wang, E. L., Zhang, L., Liu, C. M., et al. (2012). Decadal trends in evaporation from global energy and water balances. Journal of Hydrometeorology, 13, 379-391.

Zhang, R. H., Sun, X. M., Wang, W. M., Xu, J. P., Zhu, Z L. \& Tian, J. (2005). An operational two-layer remote sensing model to estimate surface flux in regional scale: Physical background. Science in China Series D-Earth Sciences, 48, 225-244.

Zhang, R. H., Tian, J., Su, H. B., Sun, X. M., Chen, S. H., \& Xia, J. (2008). Two improvements of an operational two-layer model for terrestrial surface heat flux retrieval. Sensors, 8 , 6165-6187. 